\title{
On Some Applications of $h$-generated Fuzzy Implications
}

\author{
DŽENAN GUŠIĆ, ADIS ALIHODŽIĆ \\ University of Sarajevo \\ Faculty of Sciences and Mathematics \\ Department of Mathematics \\ Zmaja od Bosne 33-35, 71000 Sarajevo \\ BOSNIA AND HERZEGOVINA \\ dzenang@pmf.unsa.ba, adis.alihodzic@pmf.unsa.ba
}

\author{
SANELA NESIMOVIĆ \\ University of Sarajevo \\ Faculty of Educational Sciences \\ Skenderija 72, 71000 Sarajevo \\ BOSNIA AND HERZEGOVINA \\ snesimovic@pf.unsa.ba
}

\begin{abstract}
In this paper we apply the $h$-generated fuzzy implications to prove a number of results which are of fundamental importance to the theory of fuzzy and vague functional and multivalued dependencies defined on given scheme. Our research is motivated by the fact that some analogous results already hold true for the families of $f$ - and $g$-generated fuzzy implications, and the fact that these three collections of implications share many similar mutual properties. While some of the aforementioned implications are introduced in order to be applied in approximate reasoning, the results derived in this paper represent the main tool in the process of automation and are alsousedtocomplementtheresolutionprinciple.Moreprecisely,themainresultofthisresearchstatesthatthe
\end{abstract}

fact that some fuzzy (vague) relation instance $r,\left.\right|^{r} \mid=2$, satisfies some fuzzy (vague) functional or fuzzy (vague) multivalued dependency ${ }_{c} \notin C$ (under assumption that $r$ satisfies some set $C$ of fuzzy (vague) functional and fuzzy (vague) multivalued dependencies), yields that the fuzzy formula attached to $c$ is valid whenever all of the fuzzy formulas attached to the elements of $C$ are valid. What is more important is that the opposite claim is also proven. Its importance stems from the fact that the verification by hand, which means purely theoretical verification, that $C$ implies ${ }_{c}$ is not required anymore. Now, in order to prove that some $C$ yields some ${ }_{c}$, it is enough to make the use of the resolution principle, and automatically verify whether or not the set of the attached fuzzy formulas yields the fuzzy formula attached to $c$. In the case of affirmative answer, the desired dependency follows. The research conducted in this paper represent a natural generalization of our previous research since it includes and considers both,fuzzyandvaguetheories.

Key-Words: Fuzzy implications, h-generators, h-implications, relations, databases.

Received: April 27, 2020. Revised: August 19, 2020. Accepted: September 10, 2020. Published: October 5, 2020

\section{Introduction}

From Yager's paper [1], it can be seen that the interest to introduce families of $f$ - an $g$-generated implications stems from a desire to consider and apply fuzzy implications in approximate reasoning (see, also [2]).

As it is known, Yager's collection of fuzzy implications is derived from functions which are either strictly decreasing or increasing, with the real interval $[0,1]$ taken to be their domain, and the interval $[0,+\infty]$ taken to be their codomain.

Thus, it is quite natural to try to obtain fuzzy implications from such functions, whose codomain is also $[0,1]$.

Indeed, Balasubramaniam, in [3] and [4], introduces a new family of fuzzy implications called $h$ generated implications (these implications are derived from the multiplicative generators of $t$-conorms).

More precisely, if $h:[0,1] \rightarrow[0,1]$ is a strictly decreasing and continuous function with $h(0)=1$, then the function $I:[0,1]^{2} \rightarrow[0,1]$, defined by

$$
I(x, y)=h^{(-1)}(x h(y))
$$

is a fuzzy implication. by

Here, $h^{(-1)}:[0,1] \rightarrow[0,1]$ is the function defined

$$
h^{(-1)}= \begin{cases}h^{-1}(x), & x \in[h(1), 1], \\ 1, & x \in[0, h(1)],\end{cases}
$$

and is called the pseudo-inverse of $h$.

Clearly, fuzzy implication $I(x, y)$ can be written without explicitly using the pseudo-inverse $h^{(-1)}$, i.e., in the form

$$
I(x, y)=h^{-1}(\max \{x h(y), h(1)\}) .
$$


Any function $h$ satisfying the properties listed above, is called an $h$-generator (of fuzzy implication $I)$.

Additionally, $I$ is called an $h$-implication, and if $I$ is generated from $h$, then we usually write $I_{h}$ instead of $I$.

Thus,

$$
I_{h}(x, y)=h^{-1}(\max \{x h(y), h(1)\}) .
$$

While the $g$-generators resp. the $f$-generators of the $g$-generated resp. $f$-generated implications are unique up to a positive constant, the $h$-generator of an $h$-generated implication is uniquely determined, i.e., $h_{1}, h_{2}$ are $h$-generators such that $I_{h_{1}}=I_{h_{2}}$ if and only if $h_{1}=h_{2}$.

It is worth to note that if $h$ is an $h$-generator of $I_{h}$, then, the natural negation $N_{I_{h}}$ is a continuous fuzzy negation, $N_{I_{h}}$ is a strict if and only if $h(1)=0$, and $N_{I_{h}}$ is strong negation if and only if $h=h^{-1}$.

Moreover, $I_{h}$ satisfies the left neutrality property, i.e.,

$$
I_{h}(1, y)=y
$$

for $y \in[0,1]$.

$I_{h}$ satisfies the exchange property, i.e.,

$$
I_{h}\left(x, I_{h}(y, z)\right)=I_{h}\left(y, I_{h}(x, z)\right)
$$

for $x, y, z \in[0,1]$.

$I_{h}$ satisfies the identity principle $I_{h}(x, x)=1, x$ $\in[0,1]$, if and only if $h(1)>0$ and $x h(x) \leq h(1)$ for every $x \in[0,1]$.

The ordering property, $x \leq y$ if and only if $I_{h}(x, y)=1, x, y \in[0,1]$, is not satisfied.

Finally, the contrapositive symmetry with respect to fuzzy negation $N$, i.e., $I_{h}(x, y)=$ $I_{h}(N(y), N(x)), x, y \in[0,1]$, is satisfied if and only if $h=h^{-1}$ and $N=N_{I_{h}}$.

In this paper, we apply the $h$-generated implications to derive some results which are closely related to the theory of fuzzy and vague database relations. The classical, ordinary database [5], accepts only the known and the exact data, the fact that forces the developer to create a restricted design which stores only such type of data. If the data is assumed to be fuzzy, then the classical relation theory is not able to answer accordingly anymore. Three approaches are developed in order to overcome these difficulties: fuzzy membership values [6], [7], possibility distributions [8], [9], [10], and the similarity relations [11], [12],
[13]. Our research follows the third approach. In this approach attribute values are described by some sets of crisp values, and the similarities between them are calculated by appropriately selected similarity relations [14]. Following the similarity based fuzzy relation concept, Yazici in [15], introduced the formal definitions of fuzzy functional and fuzzy multivalued dependencies, describing the corresponding inference rules and proving them to be sound and complete. The research is continued in [16], [17], and further on in [18], [19], [20], [21] and [22], in the case of vague functional and vague multivalued dependencies setting. The current research generalizes the previous ones by assuming both theories together, fuzzy and vague at the same time. In the main result of this paper, Theorem 2, the authors prove that the theoretical approach to new fuzzy (vague) functional (multivalued) dependencies may be circumvented, and replaced by the automated one which assumes the use of software to verify whether or not some fuzzy (vague) functional (multivalued) dependency follows from some set of fuzzy (vague) functional and fuzzy (vague) multivalued dependencies. Note that the authors do not offer an application to support their results. However, it is clear that such an application could be made by following step by step instructions described in detail by Example 1.

\section{Preliminary Results}

Suppose that $(X, m, Y, \theta, F)$ resp. $(X, m, Y, \theta, V)$ is satisfied by $r$, and that $C o n\left(t_{1}, t_{2}, A\right) \geq \theta$ for all $A \in X$, where $(X, m, Y, \theta, F)$ resp. $(X, m, Y, \theta, V)$ is a fuzzy resp. vague multivalued dependency on given scheme $S \operatorname{ch}\left(A_{1}, A_{2}, \ldots, A_{n}\right), r=\left\{t_{1}, t_{2}\right\}$ is a two-element fuzzy (vague) relation instance on $\operatorname{Sch}\left(A_{1}, A_{2}, \ldots, A_{n}\right)$, and $\operatorname{Con}\left(t_{1}, t_{2}, A\right)$ is the conformance between tuples $t_{1}$ and $t_{2}$ on attribute $A \in X$ $\subseteq\left\{A_{1}, A_{2}, \ldots, A_{n}\right\}$.

Our research will not depend on the choice between $(X, m, Y, \theta, F)$ and $(X, m, Y, \theta, V)$.

Hence, we shall focus our attention to the first, fuzzy case.

Since $(X, m, Y, \theta, F)$ is satisfied by $r$, and the inequalities $C$ on $\left(t_{1}, t_{2}, A\right) \geq \theta$ hold true for $A \in X$, it easily follows that either the inequalities

$$
\operatorname{Con}\left(t_{1}, t_{2}, X\right) \geq \theta, \operatorname{Con}\left(t_{1}, t_{2}, Y\right) \geq \theta,
$$

or the inequalities

$$
\operatorname{Con}\left(t_{1}, t_{2}, X\right) \geq \theta, \operatorname{Con}\left(t_{1}, t_{2}, Z\right) \geq \theta,
$$


hold also true (note that the opposite assertion holds also true), where (for example)

$$
\operatorname{Con}\left(t_{1}, t_{2}, X\right)=\min \left\{\operatorname{Con}\left(t_{1}, t_{2}, A\right): A \in X\right\}
$$

is the conformance between tuples $t_{1}$ and $t_{2}$ on set of attributes $X\left(\subseteq\left\{A_{1}, A_{2}, \ldots, A_{n}\right\}\right)$, and $Z=$ $\left\{A_{1}, A_{2}, \ldots, A_{n}\right\} \backslash(X \cup Y)$ (see, e.g., [21]).

For the sake of simplicity and clarity, suppose that

$$
\operatorname{Con}\left(t_{1}, t_{2}, X\right) \geq \theta, \operatorname{Con}\left(t_{1}, t_{2}, Y\right) \geq \theta \text {. }
$$

Since $\operatorname{Con}\left(t_{1}, t_{2}, X\right) \geq \theta$, Con $\left(t_{1}, t_{2}, Y\right) \geq \theta$, we obtain that $\operatorname{Con}\left(t_{1}, t_{2}, A\right) \geq \theta, A \in X$, and $C o n\left(t_{1}, t_{2}, B\right) \geq \theta, B \in Y$.

Consequently, $\operatorname{Val}_{r}^{\theta}(A)>\frac{1}{2}, A \in X$, and $\operatorname{Val}_{r}^{\theta}(B)>\frac{1}{2}, B \in Y$, where $\operatorname{Val}_{r}^{\theta}$ denotes a valuation determined by $r$ and $\theta$.

Hence,

$$
\begin{aligned}
& V a l_{r}^{\theta}\left(\&_{A \in X} A\right)=\min \left\{\operatorname{Val}_{r}^{\theta}(A): A \in X\right\}>\frac{1}{2}, \\
& \operatorname{Val}_{r}^{\theta}\left(\&_{B \in Y} B\right)=\min \left\{\operatorname{Val}_{r}^{\theta}(B): B \in Y\right\}>\frac{1}{2} .
\end{aligned}
$$

Note that this discussion yields that $\operatorname{Con}\left(t_{1}, t_{2}, X\right) \geq \theta$ if and only if $\operatorname{Val}_{r}^{\theta}\left(\&_{A \in X} A\right)>$ $\frac{1}{2}$ (in the same way as $\operatorname{Con}\left(t_{1}, t_{2}, A\right) \geq \theta$ if and only if $\left.\operatorname{Val}_{r}^{\theta}(A)>\frac{1}{2}\right)$.

Let

$$
F_{X, Y}^{m}=\left(\&_{A \in X} A\right) \rightarrow\left(\left(\&_{B \in Y} B\right) \|\left(\&_{C \in Z} C\right)\right)
$$

be the fuzzy formula attached to $(X, m, Y, \theta, F)$.

It follows that

$$
\begin{aligned}
& \operatorname{Val}_{r}^{\theta}\left(F_{X, Y}^{m}\right) \\
= & \operatorname{Val}_{r}^{\theta}\left(\left(\&_{A \in X} A\right) \rightarrow\left(\left(\&_{B \in Y} B\right) \|\left(\&_{C \in Z} C\right)\right)\right) \\
= & h^{-1}\left(\operatorname { m a x } \left\{\operatorname{Val}_{r}^{\theta}\left(\&_{A \in X} A\right) \times\right.\right.
\end{aligned}
$$

$$
\begin{aligned}
& \left.\left.\times h\left(\operatorname{Val}_{r}^{\theta}\left(\left(\&_{B \in Y} B\right) \|\left(\&_{C \in Z} C\right)\right)\right), h(1)\right\}\right) \\
= & h^{-1}\left(\operatorname { m a x } \left\{\operatorname{Val}_{r}^{\theta}\left(\&_{A \in X} A\right) \times\right.\right. \\
& \times h\left(\max \left\{\operatorname{Val}_{r}^{\theta}\left(\&_{B \in Y} B\right), \operatorname{Val}_{r}^{\theta}\left(\&_{C \in Z} C\right)\right\}\right), \\
& h(1)\}) .
\end{aligned}
$$

Denote,

$$
\begin{aligned}
& x=V a l_{r}^{\theta}\left(\&_{A \in X} A\right), \\
& y=\max \left\{V a l_{r}^{\theta}\left(\&_{B \in Y} B\right), \operatorname{Val}_{r}^{\theta}\left(\&_{C \in Z} C\right)\right\} .
\end{aligned}
$$

Hence,

$$
\operatorname{Val}_{r}^{\theta}\left(F_{X, Y}^{m}\right)=h^{-1}(\max \{x h(y), h(1)\}) .
$$

Since $V a l_{r}^{\theta}\left(\&_{A \in X} A\right)>\frac{1}{2}, \operatorname{Val}_{r}^{\theta}\left(\&_{B \in Y} B\right)>\frac{1}{2}$, it follows that $x>\frac{1}{2}$, and

$$
y=\max \left\{\operatorname{Val} l_{r}^{\theta}\left(\&_{B \in Y} B\right), \operatorname{Val}_{r}^{\theta}\left(\&_{C \in Z} C\right)\right\}>\frac{1}{2} .
$$

Suppose that

$$
\max \{x h(y), h(1)\}=h(1) .
$$

It follows immediately that

$$
\operatorname{Val}_{r}^{\theta}\left(F_{X, Y}^{m}\right)=h^{-1}(h(1))=1>\frac{1}{2} .
$$

Now, suppose that

$$
\max \{x h(y), h(1)\}=x h(y) .
$$

Since $\frac{1}{2}<x \leq 1$, we know that $x h(y) \leq h(y)$.

The fact that $h$ is a strictly decreasing function, and $\frac{1}{2}<y$, imply that $h\left(\frac{1}{2}\right)>h(y)$.

Thus, $x h(y)<h\left(\frac{1}{2}\right)$, so 


$$
\begin{aligned}
\operatorname{Val}_{r}^{\theta}\left(F_{X, Y}^{m}\right) & =h^{-1}(x h(y))>h^{-1}\left(h\left(\frac{1}{2}\right)\right) \\
& =\frac{1}{2} .
\end{aligned}
$$

Thus, the fact that $\operatorname{Con}\left(t_{1}, t_{2}, X\right) \geq \theta$, Con $\left(t_{1}, t_{2}, Y\right) \geq \theta$, yields that $C o n\left(t_{1}, t_{2}, X\right) \geq \theta$, and $\operatorname{Val}_{r}^{\theta}\left(F_{X, Y}^{m}\right)>\frac{1}{2}$.

Now, it is clear that the assumption $\operatorname{Con}\left(t_{1}, t_{2}, X\right) \geq \theta, \operatorname{Con}\left(t_{1}, t_{2}, Z\right) \geq \theta$, would yield that $\operatorname{Con}\left(t_{1}, t_{2}, X\right) \geq \theta$, and $\operatorname{Val}_{r}^{\theta}\left(F_{X, Y}^{m}\right)>\frac{1}{2}$.

This actually means that the fact that $(X, m, Y, \theta, F)$ is satisfied by $r$, and $\operatorname{Con}\left(t_{1}, t_{2}, A\right)$ $\geq \theta, A \in X$, imply that $C o n\left(t_{1}, t_{2}, X\right) \geq \theta$, and $\operatorname{Val}_{r}^{\theta}\left(F_{X, Y}^{m}\right)>\frac{1}{2}$.

Now suppose that $C o n\left(t_{1}, t_{2}, X\right) \geq \theta$, and $\operatorname{Val}_{r}^{\theta}\left(F_{X, Y}^{m}\right)>\frac{1}{2}$.

We have,

$$
\operatorname{Val}_{r}^{\theta}\left(F_{X, Y}^{m}\right)=h^{-1}(\max \{x h(y), h(1)\})>\frac{1}{2},
$$

where, as earlier,

$$
\begin{aligned}
& x=V a l_{r}^{\theta}\left(\&_{A \in X} A\right), \\
& y=\max \left\{V a l_{r}^{\theta}\left(\&_{B \in Y} B\right), V a l_{r}^{\theta}\left(\&_{C \in Z} C\right)\right\} .
\end{aligned}
$$

As noted above, $C o n\left(t_{1}, t_{2}, X\right) \geq \theta$ implies that $x=\operatorname{Val} l_{r}^{\theta}\left(\&_{A \in X} A\right)>\frac{1}{2}$.

Since $\operatorname{Val}_{r}^{\theta}\left(F_{X, Y}^{m}\right)>\frac{1}{2}$, and $h$ is a decreasing function, it follows that

$$
\max \{x h(y), h(1)\}<h\left(\frac{1}{2}\right) .
$$

If $\max \{x h(y), h(1)\}=h(1)$, then

$$
x h(y) \leq h(1)<h\left(\frac{1}{2}\right) .
$$

Otherwise, if $\max \{x h(y), h(1)\}=x h(y)$, then we immediately have that $x h(y)<h\left(\frac{1}{2}\right)$.
If $h(y)=0$, then the fact that $h$ is a strictly decreasing function, implies that $y=1$.

Namely, if we assume that $y<1$, then, for any $a$, such that $y<a<1$, holds that $0=h(y)>h(a)$.

This is a contradiction, however.

Thus, $y=1>\frac{1}{2}$.

Suppose that $h(y)>0$.

We obtain,

$$
x<\frac{h\left(\frac{1}{2}\right)}{h(y)} .
$$

Note that $x>\frac{1}{2}$.

This means that the inequality $x<\frac{h\left(\frac{1}{2}\right)}{h(y)}$ must be true for all $\frac{1}{2}<x \leq 1$.

In particular, the inequality $1<\frac{h\left(\frac{1}{2}\right)}{h(y)}$ must be satisfied.

We obtain, $h(y)<h\left(\frac{1}{2}\right)$, and hence $y>\frac{1}{2}$.

We conclude that the inequality $y>\frac{1}{2}$ holds always true.

Since $y=$ $\max \left\{\operatorname{Val}_{r}^{\theta}\left(\&_{B \in Y} B\right), \operatorname{Val}_{r}^{\theta}\left(\&_{C \in Z} C\right)\right\}$, it follows that $\operatorname{Val}_{r}^{\theta}\left(\&_{B \in Y} B\right)>\frac{1}{2}$ and $\operatorname{Val}_{r}^{\theta}\left(\&_{C \in Z} C\right)>\frac{1}{2}$.

As noted before, we obtain that $\operatorname{Con}\left(t_{1}, t_{2}, Y\right) \geq$ $\theta$ and $C o n\left(t_{1}, t_{2}, Z\right) \geq \theta$.

Thus, $C o n\left(t_{1}, t_{2}, X\right) \geq \theta, \operatorname{Con}\left(t_{1}, t_{2}, Y\right) \geq$ $\theta$ or $\operatorname{Con}\left(t_{1}, t_{2}, X\right) \geq \theta, \operatorname{Con}\left(t_{1}, t_{2}, Z\right) \geq \theta$, so $(X, m, Y, \theta, F)$ is satisfied by $r$, and $\operatorname{Con}\left(t_{1}, t_{2}, A\right)$ $\geq \theta, A \in X$.

Combining what we derived above, we end up with the conclusion that $(X, m, Y, \theta, F)$ is satisfied by $r$, and $C o n\left(t_{1}, t_{2}, A\right) \geq \theta, A \in X$, if and only if $\operatorname{Con}\left(t_{1}, t_{2}, X\right) \geq \theta$, and $\operatorname{Val}_{r}^{\theta}\left(F_{X, Y}^{m}\right)>\frac{1}{2}$.

\section{Main Result}

Besides fuzzy resp. vague multivalued dependencies $(X, m, Y, \theta, F)$ resp. $(X, m, Y, \theta, V)$, we consider fuzzy resp. vague functional dependencies $(X, f, Y, \theta, F)$ resp. $(X, f, Y, \theta, V)$.

Since the discussion does not depend on the choice between $(X, f, Y, \theta, F)$ and $(X, f, Y, \theta, V)$, we shall pay our attention to fuzzy functional resp. fuzzy multivalued dependencies $(X, f, Y, \theta, F)$ resp. $(X, m, Y, \theta, F)$.

We already attached the fuzzy formula $F_{X, Y}^{m}$ to fuzzy multivalued dependency $(X, m, Y, \theta, F)$.

Now, we put

$$
F_{X, Y}^{f}=\left(\&_{A \in X} A\right) \rightarrow\left(\&_{B \in Y} B\right)
$$


to be fuzzy formula attached to $(X, f, Y, \theta, F)$.

In the sequel, we shall denote by $C$, the set of fuzzy functional and fuzzy multivalued dependencies $\left(K, f, L, \theta_{2}, F\right)$ and $\left(K, m, L, \theta_{2}, F\right)$.

Consequently, we shall put $C^{\prime}$ to be the corresponding set of fuzzy formulas $F_{K, L}^{f}$ and $F_{K, L}^{m}$, where, in the multivalued case, the difference $\left\{A_{1}, A_{2}, \ldots, A_{n}\right\} \backslash(K \cup L)$ will be denoted by $M$.

Besides the set $C$, we shall consider some fuzzy functonal resp. fuzzy multivalued dependency $\left(X, f, Y, \theta_{1}, F\right)$ resp. $\left(X, m, Y, \theta_{1}, F\right)$.

The corresponding fuzzy formula $F_{X, Y}^{f}$ resp. $F_{X, Y}^{m}$ will be denoted by $c^{\prime}$, with $\left\{A_{1}, A_{2}, \ldots, A_{n}\right\} \backslash$ $(X \cup Y)$ denoted by $Z$.

As it is usual, we say that $\left(X, f, Y, \theta_{1}, F\right)$ is satisfied by $r$ ( $r$ is arbitrary), if for $t_{1}, t_{2} \in r$,

$$
\operatorname{Con}\left(t_{1}, t_{2}, Y\right) \geq \min \left\{\theta_{1}, \operatorname{Con}\left(t_{1}, t_{2}, X\right)\right\} \text {. }
$$

For the sake of simplicity, if $\left(X, f, Y, \theta_{1}, F\right)$ is satisfied by $r$, we shall say that $\left(t_{1}, t_{2}, Y, \theta_{1}, X, r\right)$ holds true (or that $\left(t^{\prime}, t^{\prime \prime}, Y, \theta_{1}, X, r\right)$ holds true, with the obvious meaning).

Furthermore, we say that $\left(X, m, Y, \theta_{1}, F\right)$ is satisfied by $r$ ( $r$ is arbitrary), if for $t_{1}, t_{2} \in r$, there is $t_{3}$ $\in r$, such that

$$
\begin{aligned}
& \text { Con }\left(t_{3}, t_{1}, X\right) \geq \min \left\{\theta_{1}, \operatorname{Con}\left(t_{1}, t_{2}, X\right)\right\}, \\
& \text { Con }\left(t_{3}, t_{1}, Y\right) \geq \min \left\{\theta_{1}, \operatorname{Con}\left(t_{1}, t_{2}, X\right)\right\}, \\
& \operatorname{Con}\left(t_{3}, t_{2}, Z\right) \geq \min \left\{\theta_{1}, \operatorname{Con}\left(t_{1}, t_{2}, X\right)\right\} .
\end{aligned}
$$

Thus, if $\left(X, m, Y, \theta_{1}, F\right)$ is satisfied by $r$, we shall say that $\left(t_{3}, t_{1}, t_{2}, X, Y, Z, \theta_{1}, r\right)$ holds true.

For example, if we say that $\left(t^{\prime \prime \prime}, t^{\prime \prime}, t^{\prime}, K, L, M, \theta_{2}, r^{\prime}\right)$ holds true, then, for $t^{\prime}, t^{\prime \prime}$ $\in r^{\prime}$, there is $t^{\prime \prime \prime} \in r^{\prime}$, such that

$$
\begin{aligned}
\operatorname{Con}\left(t^{\prime \prime \prime}, t^{\prime \prime}, K\right) & \geq \min \left\{\theta_{2}, \operatorname{Con}\left(t^{\prime \prime}, t^{\prime}, K\right)\right\} \\
& =\min \left\{\theta_{2}, \operatorname{Con}\left(t^{\prime}, t^{\prime \prime}, K\right)\right\}, \\
\operatorname{Con}\left(t^{\prime \prime \prime}, t^{\prime \prime}, L\right) & \geq \min \left\{\theta_{2}, \operatorname{Con}\left(t^{\prime}, t^{\prime \prime}, K\right)\right\}, \\
\operatorname{Con}\left(t^{\prime \prime \prime}, t^{\prime}, M\right) & \geq \min \left\{\theta_{2}, \operatorname{Con}\left(t^{\prime}, t^{\prime \prime}, K\right)\right\} .
\end{aligned}
$$

Now, suppose that $\left(X, f, Y, \theta_{1}, F\right)$ resp. $\left(X, m, Y, \theta_{1}, F\right)$ is satisfied by $r$ if $\left(K, f, L, \theta_{2}, F\right)$ is satisfied by $r$, and $\left(K, m, L, \theta_{2}, F\right)$ is satisfied by $r$ for all $\left(K, f, L, \theta_{2}, F\right) \in C$ and all $\left(K, m, L, \theta_{2}, F\right)$ $\in C$, where $r$ is a two-element fuzzy relation instance on given scheme $\operatorname{Sch}\left(A_{1}, A_{2}, \ldots, A_{n}\right)$.

We shall prove that $\operatorname{Val}_{r}^{\beta}\left(c^{\prime}\right)>\frac{1}{2}$ for every valuation $V a l_{r}^{\beta}$, such that $\operatorname{Val}_{r}^{\beta}\left(F_{K, L}^{f}\right)>\frac{1}{2}$ and $\operatorname{Val}_{r}^{\beta}\left(F_{K, L}^{m}\right)>\frac{1}{2}$ for all $F_{K, L}^{f} \in C^{\prime}$ and all $F_{K, L}^{m}$ $\in C^{\prime}$.

Suppose that the last statement is not satisfied.

This means that there exists some valuation $V a l_{r}^{\beta}$ (attached to some two-element $r=\left\{t_{1}, t_{2}\right\}$ and $\beta \in$ $[0,1])$, such that $\operatorname{Val}_{r}^{\beta}\left(F_{K, L}^{f}\right)>\frac{1}{2}, F_{K, L}^{f} \in C^{\prime}$, and $\operatorname{Val}_{r}^{\beta}\left(F_{K, L}^{m}\right)>\frac{1}{2}, F_{K, L}^{m} \in C^{\prime}$, but $\operatorname{Val}_{r}^{\beta}\left(c^{\prime}\right) \leq \frac{1}{2}$.

Denote by $Z^{\prime}$ the set

$$
Z^{\prime}=\left\{A \in\left\{A_{1}, A_{2}, \ldots, A_{n}\right\}: \operatorname{Val}_{r}^{\beta}(A)>\frac{1}{2}\right\} .
$$

First, suppose that $Z^{\prime} \neq \emptyset$.

It follows that $\operatorname{Val}_{r}^{\beta}(A) \leq \frac{1}{2}$ for all $A \in$ $\left\{A_{1}, A_{2}, \ldots, A_{n}\right\}$.

Having in mind that $\operatorname{Val}_{r}^{\beta}\left(c^{\prime}\right) \leq \frac{1}{2}$, we obtain that $\operatorname{Val}_{r}^{\beta}\left(F_{X, Y}^{f}\right) \leq \frac{1}{2}$ resp. $\operatorname{Val}_{r}^{\beta}\left(F_{X, Y}^{m}\right) \leq \frac{1}{2}$, i.e., that

$$
\begin{aligned}
& \operatorname{Val}_{r}^{\beta}\left(\left(\&_{A \in X} A\right) \rightarrow\left(\&_{B \in Y} B\right)\right) \\
= & h^{-1}\left(\operatorname { m a x } \left\{\operatorname{Val}_{r}^{\beta}\left(\&_{A \in X} A\right) \times\right.\right. \\
& \left.\left.\times h\left(\operatorname{Val}_{r}^{\beta}\left(\&_{B \in Y} B\right)\right), h(1)\right\}\right) \\
\leq & \frac{1}{2}
\end{aligned}
$$

resp.

$$
\begin{aligned}
& \operatorname{Val}_{r}^{\beta}\left(\left(\&_{A \in X} A\right) \rightarrow\left(\left(\&_{B \in Y} B\right) \|\left(\&_{C \in Z} C\right)\right)\right) \\
= & h^{-1}\left(\operatorname { m a x } \left\{\operatorname{Val}_{r}^{\beta}\left(\&_{A \in X} A\right) \times\right.\right. \\
& \left.\left.\times h\left(\operatorname{Val}_{r}^{\beta}\left(\left(\&_{B \in Y} B\right) \|\left(\&_{C \in Z} C\right)\right)\right), h(1)\right\}\right) \\
= & h^{-1}\left(\operatorname { m a x } \left\{\operatorname{Val}_{r}^{\beta}\left(\&_{A \in X} A\right) \times\right.\right.
\end{aligned}
$$


$\times h\left(\max \left\{V a l_{r}^{\beta}\left(\&_{B \in Y} B\right), V a l_{r}^{\beta}\left(\&_{C \in Z} C\right)\right\}\right)$,

$h(1)\})$

$\leq \frac{1}{2}$

Thus, the fact that $h$ is a decreasing function, yields that

$$
\begin{aligned}
& \max \left\{\operatorname{Val}_{r}^{\beta}\left(\&_{A \in X} A\right) \times\right. \\
& \left.\times h\left(\operatorname{Val}_{r}^{\beta}\left(\&_{B \in Y} B\right)\right), h(1)\right\} \geq h\left(\frac{1}{2}\right)
\end{aligned}
$$

resp.

$$
\begin{aligned}
& \max \left\{\operatorname{Val}_{r}^{\beta}\left(\&_{A \in X} A\right) \times\right. \\
& \times h\left(\max \left\{\operatorname{Val}_{r}^{\beta}\left(\&_{B \in Y} B\right), \operatorname{Val}_{r}^{\beta}\left(\&_{C \in Z} C\right)\right\}\right), \\
& h(1)\} \geq h\left(\frac{1}{2}\right) .
\end{aligned}
$$

Since $\frac{1}{2}<1$ and $h$ is strictly decreasing, we have that $h\left(\frac{1}{2}\right)>h(1)$.$$
\text { If }
$$

$$
\begin{aligned}
& \max \left\{\operatorname{Val}_{r}^{\beta}\left(\&_{A \in X} A\right) \times\right. \\
& \left.\times h\left(\operatorname{Val}_{r}^{\beta}\left(\&_{B \in Y} B\right)\right), h(1)\right\}=h(1),
\end{aligned}
$$

then, $h(1) \geq h\left(\frac{1}{2}\right)$.

This is a contradiction.

Similarly, if

$$
\begin{aligned}
& \max \left\{\operatorname{Val}_{r}^{\beta}\left(\&_{A \in X} A\right) \times\right. \\
& \times h\left(\max \left\{V a l_{r}^{\beta}\left(\&_{B \in Y} B\right), \operatorname{Val}_{r}^{\beta}\left(\&_{C \in Z} C\right)\right\}\right), \\
& h(1)\}=h(1),
\end{aligned}
$$

then $h(1) \geq h\left(\frac{1}{2}\right)$.

This is a contradiction.
We conclude,

$$
\begin{aligned}
& \operatorname{Val}_{r}^{\beta}\left(\&_{A \in X} A\right) h\left(\operatorname{Val}_{r}^{\beta}\left(\&_{B \in Y} B\right)\right) \\
= & \max \left\{\operatorname{Val}_{r}^{\beta}\left(\&_{A \in X} A\right) \times\right. \\
& \left.\times h\left(\operatorname{Val}_{r}^{\beta}\left(\&_{B \in Y} B\right)\right), h(1)\right\} \\
\geq & h\left(\frac{1}{2}\right)
\end{aligned}
$$

resp.

$$
\begin{aligned}
& \operatorname{Val}_{r}^{\beta}\left(\&_{A \in X} A\right) h\left(\operatorname { m a x } \left\{\operatorname{Val}_{r}^{\beta}\left(\&_{B \in Y} B\right),\right.\right. \\
& \left.\left.\operatorname{Val}_{r}^{\beta}\left(\&_{C \in Z} C\right)\right\}\right) \\
& =\max \left\{\operatorname{Val} l_{r}^{\beta}\left(\&_{A \in X} A\right) \times\right. \\
& \times h\left(\operatorname { m a x } \left\{\operatorname{Val} l_{r}^{\beta}\left(\&_{B \in Y} B\right),\right.\right. \\
& \left.\left.\left.\operatorname{Val}_{r}^{\beta}\left(\&_{C \in Z} C\right)\right\}\right), h(1)\right\} \\
& \geq h\left(\frac{1}{2}\right) . \\
& \text { If } \quad h\left(\operatorname{Val}_{r}^{\beta}\left(\&_{B \in Y} B\right)\right)=0
\end{aligned}
$$

resp.

$$
\begin{aligned}
& h\left(\operatorname { m a x } \left\{V a l_{r}^{\beta}\left(\&_{B \in Y} B\right),\right.\right. \\
& \left.\left.V a l_{r}^{\beta}\left(\&_{C \in Z} C\right)\right\}\right)=0,
\end{aligned}
$$

then, the assumptions on $h$ yield that

$$
\operatorname{Val}_{r}^{\beta}\left(\&_{B \in Y} B\right)=1
$$

resp.

$$
\max \left\{\operatorname{Val} l_{r}^{\beta}\left(\&_{B \in Y} B\right), \operatorname{Val}_{r}^{\beta}\left(\&_{C \in Z} C\right)\right\}=1 .
$$
$=1$. 
Since, for example,

$$
V a l_{r}^{\beta}\left(\&_{B \in Y} B\right)=\left\{\operatorname{Val}_{r}^{\beta}(B): B \in Y\right\}
$$

it follows that $\frac{1}{2}<1=\operatorname{Val}_{r}^{\beta}\left(\&_{B \in Y} B\right)=\operatorname{Val}_{r}^{\beta}(B)$ for some $B \in Y \subseteq\left\{A_{1}, A_{2}, \ldots, A_{n}\right\}$, and $\frac{1}{2}<1$ $=\operatorname{Val}_{r}^{\beta}\left(\&_{C \in Z} C\right)=\operatorname{Val}_{r}^{\beta}(C)$ for some $C \in Z \subseteq$ $\left\{A_{1}, A_{2}, \ldots, A_{n}\right\}$.

Both of thee cases contradicts the fact that $\operatorname{Val}_{r}^{\beta}(A) \leq \frac{1}{2}$ for all $A \in\left\{A_{1}, A_{2}, \ldots, A_{n}\right\}$.

Therefore,

$$
h\left(\operatorname{Val}_{r}^{\beta}\left(\&_{B \in Y} B\right)\right)>0
$$

resp.

$$
\begin{aligned}
& h\left(\operatorname { m a x } \left\{V a l_{r}^{\beta}\left(\&_{B \in Y} B\right),\right.\right. \\
& \left.\left.V a l_{r}^{\beta}\left(\&_{C \in Z} C\right)\right\}\right)>0 .
\end{aligned}
$$

We obtain that,

$$
\geq \frac{\operatorname{Val}_{r}^{\beta}\left(\&_{A \in X} A\right)}{h\left(\operatorname{Val}_{r}^{\beta}\left(\&_{B \in Y} B\right)\right)}
$$

resp.

$$
\begin{gathered}
\operatorname{Val} l_{r}^{\beta}\left(\&_{A \in X} A\right) \\
\geq \frac{h\left(\frac{1}{2}\right)}{h\left(\max \left\{V a l_{r}^{\beta}\left(\&_{B \in Y} B\right), V a l_{r}^{\beta}\left(\&_{C \in Z} C\right)\right\}\right)}
\end{gathered}
$$

Since $\operatorname{Val}_{r}^{\beta}(A) \leq \frac{1}{2}$ for all $A \in\left\{A_{1}, A_{2}, \ldots, A_{n}\right\}$, we have that

$$
V a l_{r}^{\beta}\left(\&_{B \in Y} B\right)=\left\{\operatorname{Val}_{r}^{\beta}(B): B \in Y\right\} \leq \frac{1}{2} .
$$

Also, $\operatorname{Val}_{r}^{\beta}\left(\&_{C \in Z} C\right) \leq \frac{1}{2}$, so

$$
\max \left\{\operatorname{Val}_{r}^{\beta}\left(\&_{B \in Y} B\right), \operatorname{Val}_{r}^{\beta}\left(\&_{C \in Z} C\right)\right\} \leq \frac{1}{2} .
$$

It follow that

$$
h\left(\operatorname{Val}_{r}^{\beta}\left(\&_{B \in Y} B\right)\right) \geq h\left(\frac{1}{2}\right)
$$

resp.

$$
\begin{aligned}
& h\left(\max \left\{\operatorname{Val}_{r}^{\beta}\left(\&_{B \in Y} B\right), V a l_{r}^{\beta}\left(\&_{C \in Z} C\right)\right\}\right) \\
\geq & h\left(\frac{1}{2}\right),
\end{aligned}
$$

i.e.,

$$
\frac{h\left(\frac{1}{2}\right)}{h\left(\operatorname{Val}_{r}^{\beta}\left(\&_{B \in Y} B\right)\right)} \leq 1
$$

resp.

$$
\frac{h\left(\frac{1}{2}\right)}{h\left(\max \left\{\operatorname{Val}_{r}^{\beta}\left(\&_{B \in Y} B\right), V a l_{r}^{\beta}\left(\&_{C \in Z} C\right)\right\}\right)}
$$

Hence, $\operatorname{Val}_{r}^{\beta}\left(\&_{A \in X} A\right)=1$.

Reasoning as earlier, we conclude that $\operatorname{Val}_{r}^{\beta}(A)$ $=1>\frac{1}{2}$ for some $A \in X \subseteq\left\{A_{1}, A_{2}, \ldots, A_{n}\right\}$.

This contradicts the fact that $\operatorname{Val}_{r}^{\beta}(A) \leq \frac{1}{2}$ for all $A \in\left\{A_{1}, A_{2}, \ldots, A_{n}\right\}$.

Since the assumption $Z^{\prime}=\emptyset$ yields to contradiction, it follows that $Z^{\prime} \neq \emptyset$.

Second, suppose that $Z^{\prime}=\left\{A_{1}, A_{2}, \ldots, A_{n}\right\}$.

It follows that $\operatorname{Val}_{r}^{\beta}(A)>\frac{1}{2}$ for all $A \in$ $\left\{A_{1}, A_{2}, \ldots, A_{n}\right\}$

Once again, the fact that $\operatorname{Val}_{r}^{\beta}\left(c^{\prime}\right) \leq \frac{1}{2}$, yields that $\operatorname{Val}_{r}^{\beta}\left(F_{X, Y}^{f}\right) \leq \frac{1}{2}$ resp. $\operatorname{Val}_{r}^{\beta}\left(F_{X, Y}^{m}\right) \leq \frac{1}{2}$, i.e., that (1) resp. (2) holds true.

If (5) resp. (4) holds true, then (1) resp. (2) implies that $h\left(\frac{1}{2}\right) \leq 0$.

This is not possible, however.

It follows that (5) resp. (6) holds true, i.e., that (7) resp. (8) holds true.

\section{Note that $\operatorname{Val}_{r}^{\beta}(A)>\frac{1}{2}$ for $A \in$} $\left\{A_{1}, A_{2}, \ldots, A_{n}\right\}$. $\frac{1}{2}$, so

Hence, $\operatorname{Val}_{r}^{\beta}\left(\&_{B \in Y} B\right)>\frac{1}{2}, \operatorname{Val}_{r}^{\beta}\left(\&_{C \in Z} C\right)>$

$$
\max \left\{\operatorname{Val}_{r}^{\beta}\left(\&_{B \in Y} B\right), \operatorname{Val}_{r}^{\beta}\left(\&_{C \in Z} C\right)\right\}>\frac{1}{2} .
$$

Now, reasoning as before, we conclude that 


$$
h\left(\operatorname{Val}_{r}^{\beta}\left(\&_{B \in Y} B\right)\right)<h\left(\frac{1}{2}\right)
$$

resp.

$$
\begin{aligned}
& h\left(\max \left\{\operatorname{Val}_{r}^{\beta}\left(\&_{B \in Y} B\right), \operatorname{Val}_{r}^{\beta}\left(\&_{C \in Z} C\right)\right\}\right) \\
< & h\left(\frac{1}{2}\right),
\end{aligned}
$$

i.e., that

$$
\frac{h\left(\frac{1}{2}\right)}{h\left(\operatorname{Val}_{r}^{\beta}\left(\&_{B \in Y} B\right)\right)}>1
$$

resp.

$$
\frac{h\left(\frac{1}{2}\right)}{h\left(\max \left\{\operatorname{Val}_{r}^{\beta}\left(\&_{B \in Y} B\right), \operatorname{Val}_{r}^{\beta}\left(\&_{C \in Z} C\right)\right\}\right)}
$$$$
>1 \text {. }
$$

By (7) resp. (8), $\operatorname{Val}_{r}^{\beta}\left(\&_{A \in X} A\right)>1$.

This is not possible, however.

So, the assumption that $Z^{\prime}=\left\{A_{1}, A_{2}, \ldots, A_{n}\right\}$, yields a contradiction.

It follows that $Z^{\prime} \subset\left\{A_{1}, A_{2}, \ldots, A_{n}\right\}$.

We have, $\emptyset \neq Z^{\prime} \subset\left\{A_{1}, A_{2}, \ldots, A_{n}\right\}$.

For the sake of simplicity, we shall assume that each of attributes in $\left\{A_{1}, A_{2}, \ldots, A_{n}\right\}$ is defined on the same two-element set $\{p, q\}$.

Strengths of the dependencies in $C$ are denoted by $\theta_{2}$, while the strength of the dependency $\left(X, f, Y, \theta_{1}, F\right)$ resp. $\left(X, m, Y, \theta_{1}, F\right)$ is obviously $\theta_{1}$.

We shall denote by $\theta^{\prime}(<1)$ the minimum of these strengths, and select some $\theta^{\prime \prime}<\theta^{\prime}$.

Since domain of each of the attributes in $\left\{A_{1}, A_{2}, \ldots, A_{n}\right\}$ is $\{p, q\}$, the similarity relation (defined on domains of the attributes in $\left.\left\{A_{1}, A_{2}, \ldots, A_{n}\right\}\right)$, is given by $\operatorname{Sim}(p, q)=\theta^{\prime \prime}$.

Clearly, $\operatorname{Sim}(p, q)=\operatorname{Sim}(q, p)=1$.

Now the fact that $\emptyset \neq Z^{\prime} \subset\left\{A_{1}, A_{2}, \ldots, A_{n}\right\}$ enables us to define the following two-element, fuzzy relation instance $r^{\prime}$, by putting it to have $t^{\prime}, t^{\prime \prime}$ values equal $p$ on $Z^{\prime}$, and $t^{\prime}, t^{\prime \prime}$ values equal $q$ on $\left\{A_{1}, A_{2}, \ldots, A_{n}\right\} \backslash Z^{\prime}$, where $r^{\prime}=\left\{t^{\prime}, t^{\prime \prime}\right\}$.
We shall prove that $\left(K, f, L, \theta_{2}, F\right)$ is satisfied by $r^{\prime}$, and that $\left(K, m, L, \theta_{2}, F\right)$ is satisfied by $r^{\prime}$ for all $\left(K, f, L, \theta_{2}, F\right) \in C$ and all $\left(K, m, L, \theta_{2}, F\right) \in C$.

Furthermore, we shall prove that $r^{\prime}$ violates $\left(X, f, Y, \theta_{1}, F\right)$ resp. $\left(X, m, Y, \theta_{2}, F\right)$.

Let $\left(K, f, L, \theta_{2}, F\right) \in C$.

By our assumption, $\operatorname{Val}_{r}^{\beta}\left(F_{K, L}^{f}\right)>\frac{1}{2}$.

Hence,

$$
\begin{aligned}
& \operatorname{Val}_{r}^{\beta}\left(\left(\&_{A \in K} A\right) \rightarrow\left(\&_{B \in L} B\right)\right) \\
= & h^{-1}\left(\operatorname { m a x } \left\{\operatorname{Val}_{r}^{\beta}\left(\&_{A \in K} A\right) \times\right.\right. \\
& \left.\left.\times h\left(\operatorname{Val}_{r}^{\beta}\left(\&_{B \in L} B\right)\right), h(1)\right\}\right)
\end{aligned}
$$

$$
>\frac{1}{2}
$$

i.e.,

$$
\begin{aligned}
& \max \left\{V a l_{r}^{\beta}\left(\&_{A \in K} A\right) \times\right. \\
& \left.\times h\left(\operatorname{Val}_{r}^{\beta}\left(\&_{B \in L} B\right)\right), h(1)\right\}<h\left(\frac{1}{2}\right) .
\end{aligned}
$$

Suppose that the maximum is $h(1)$.

Then,

$$
\begin{aligned}
& \operatorname{Val}_{r}^{\beta}\left(\&_{A \in K} A\right) h\left(\operatorname{Val}_{r}^{\beta}\left(\&_{B \in L} B\right)\right) \\
\leq & h(1)<h\left(\frac{1}{2}\right) .
\end{aligned}
$$

If the maximum is

$$
\operatorname{Val}_{r}^{\beta}\left(\&_{A \in K} A\right) h\left(\operatorname{Val}_{r}^{\beta}\left(\&_{B \in L} B\right)\right),
$$

then, once again

$$
\operatorname{Val}_{r}^{\beta}\left(\&_{A \in K} A\right) h\left(\operatorname{Val}_{r}^{\beta}\left(\&_{B \in L} B\right)\right)<h\left(\frac{1}{2}\right) .
$$

If $V a l_{r}^{\beta}\left(\&_{A \in K} A\right) \leq \frac{1}{2}$, then $\operatorname{Val}_{r}^{\beta}(A) \leq \frac{1}{2}$ for all $A \in K$, so $A \notin Z^{\prime}$, and hence $C o n\left(t^{\prime}, t^{\prime \prime}, A\right)=$ $\theta^{\prime \prime}$.

Thus, $C$ on $\left(t^{\prime}, t^{\prime \prime}, K\right)=\theta^{\prime \prime}$. 
By our definition of similarity relations on domains of attributes in $\left\{A_{1}, A_{2}, \ldots, A_{n}\right\}$, it immediately follows that $\operatorname{Con}\left(t^{\prime}, t^{\prime \prime}, Q\right) \geq \theta^{\prime \prime}$ for any $Q \subseteq$ $\left\{A_{1}, A_{2}, \ldots, A_{n}\right\}$.

In particular, $\operatorname{Con}\left(t^{\prime}, t^{\prime \prime}, L\right) \geq \theta^{\prime \prime}$.

Hence,

$$
\begin{aligned}
& \operatorname{Con}\left(t^{\prime}, t^{\prime \prime}, L\right) \\
& \geq \theta^{\prime \prime}=\min \left\{\theta_{2}, \theta^{\prime \prime}\right\}=\min \left\{\theta_{2}, \operatorname{Con}\left(t^{\prime}, t^{\prime \prime}, K\right)\right\},
\end{aligned}
$$

i.e., $\left(K, f, L, \theta_{2}, F\right)$ is satisfied by $r^{\prime}$, i.e., $\left(t^{\prime}, t^{\prime \prime}, L, \theta_{2}, K, r^{\prime}\right)$ holds true.

If $\operatorname{Val}_{r}^{\beta}\left(\&_{A \in K} A\right)>\frac{1}{2}$, then $\operatorname{Val}_{r}^{\beta}(A)>\frac{1}{2}$ for all $A \in K$, so $A \in Z^{\prime}$ for all $A \in K$, and hence Con $\left(t^{\prime}, t^{\prime \prime}, A\right)=1$ for all $A \in K$.

Thus, $C o n\left(t^{\prime}, t^{\prime \prime}, K\right)=1$.

If $h\left(\operatorname{Val}_{r}^{\beta}\left(\&_{B \in L} B\right)\right)=0$, then $\operatorname{Val}_{r}^{\beta}\left(\&_{B \in L} B\right)$ $=1>\frac{1}{2}$.

Reasoning as in the case $\operatorname{Val}_{r}^{\beta}\left(\&_{A \in K} A\right)>\frac{1}{2}$, we obtain that $\operatorname{Con}\left(t^{\prime}, t^{\prime \prime}, L\right)=1$.

Hence,

$$
\begin{aligned}
& \operatorname{Con}\left(t^{\prime}, t^{\prime \prime}, L\right) \\
= & 1 \geq \theta_{2}=\min \left\{\theta_{2}, 1\right\} \\
= & \min \left\{\theta_{2}, \operatorname{Con}\left(t^{\prime}, t^{\prime \prime}, K\right)\right\},
\end{aligned}
$$

i.e., $\left(t^{\prime}, t^{\prime \prime}, L, \theta_{2}, K, r^{\prime}\right)$ holds true.

Suppose that $h\left(\operatorname{Val}_{r}^{\beta}\left(\&_{B \in L} B\right)\right)>0$.

We obtain,

$$
\operatorname{Val}_{r}^{\beta}\left(\&_{A \in K} A\right)<\frac{h\left(\frac{1}{2}\right)}{h\left(\operatorname{Val}_{r}^{\beta}\left(\&_{B \in L} B\right)\right)} .
$$

Since $\operatorname{Val}_{r}^{\beta}\left(\&_{A \in K} A\right)>\frac{1}{2}$, it follows that

$$
\frac{h\left(\frac{1}{2}\right)}{h\left(\operatorname{Val}_{r}^{\beta}\left(\&_{B \in L} B\right)\right)}>1,
$$

i.e.,

$$
h\left(\operatorname{Val}_{r}^{\beta}\left(\&_{B \in L} B\right)\right)<h\left(\frac{1}{2}\right),
$$

i.e., $\operatorname{Val}_{r}^{\beta}\left(\&_{B \in L} B\right)>\frac{1}{2}$.

Hence, as in the case $\operatorname{Val}_{r}^{\beta}\left(\&_{B \in L} B\right)=1>\frac{1}{2}$, we conclude that $\left(t^{\prime}, t^{\prime \prime}, L, \theta_{2}, K, r^{\prime}\right)$ holds true.

Now, let $\left(K, m, L, \theta_{2}, F\right) \in C$.

By our assumption, $\operatorname{Val}_{r}^{\beta}\left(F_{K, L}^{m}\right)>\frac{1}{2}$.

Thus,

$$
\begin{aligned}
& \operatorname{Val}_{r}^{\beta}\left(\left(\&_{A \in K} A\right) \rightarrow\left(\left(\&_{B \in L} B\right) \|\left(\&_{C \in M} C\right)\right)\right) \\
= & h^{-1}\left(\operatorname { m a x } \left\{V a l_{r}^{\beta}\left(\&_{A \in K} A\right) \times\right.\right. \\
& \left.\left.\times h\left(\operatorname{Val}_{r}^{\beta}\left(\left(\&_{B \in L} B\right) \|\left(\&_{C \in M} C\right)\right)\right), h(1)\right\}\right) \\
= & h^{-1}\left(\operatorname { m a x } \left\{V a l_{r}^{\beta}\left(\&_{A \in K} A\right) \times\right.\right. \\
& \times h\left(\max \left\{\operatorname{Val}_{r}^{\beta}\left(\&_{B \in L} B\right), \operatorname{Val}_{r}^{\beta}\left(\&_{C \in M} C\right)\right\}\right), \\
& h(1)\}) \\
> & \frac{1}{2} .
\end{aligned}
$$

i.e.,

$$
\begin{aligned}
& \max \left\{\operatorname{Val}_{r}^{\beta}\left(\&_{A \in K} A\right) \times\right. \\
& \times h\left(\max \left\{\operatorname{Val}_{r}^{\beta}\left(\&_{B \in L} B\right), \operatorname{Val}_{r}^{\beta}\left(\&_{C \in M} C\right)\right\}\right), \\
& h(1)\}<h\left(\frac{1}{2}\right) .
\end{aligned}
$$

Reasoning in the same way as in the fuzzy functional case, we conclude that the last inequality yields that

$$
\begin{aligned}
& V_{a l_{r}^{\beta}\left(\&_{A \in K} A\right) \times} \\
& \times h\left(\max \left\{\operatorname{Val}_{r}^{\beta}\left(\&_{B \in L} B\right), \operatorname{Val}_{r}^{\beta}\left(\&_{C \in M} C\right)\right\}\right) \\
& <h\left(\frac{1}{2}\right) .
\end{aligned}
$$

If $\operatorname{Val}_{r}^{\beta}\left(\&_{A \in K} A\right) \leq \frac{1}{2}$, then, as before, $\operatorname{Con}\left(t^{\prime}, t^{\prime \prime}, K\right)=\theta^{\prime \prime}$. 
Thus, there is $t^{\prime \prime \prime} \in r^{\prime}, t^{\prime \prime \prime}=t^{\prime}$, such that $\left(t^{\prime \prime \prime}, t^{\prime}, t^{\prime \prime}, K, L, M, \theta_{2}, r^{\prime}\right)$ holds true.

If $\operatorname{Val}_{r}^{\beta}\left(\&_{A \in K} A\right)>\frac{1}{2}$, then, as earlier, $C o n$
If

$h\left(\max \left\{V a l_{r}^{\beta}\left(\&_{B \in L} B\right), V a l_{r}^{\beta}\left(\&_{C \in M} C\right)\right\}\right)=0$,

then

$$
\max \left\{\operatorname{Val}_{r}^{\beta}\left(\&_{B \in L} B\right), \operatorname{Val}_{r}^{\beta}\left(\&_{C \in M} C\right)\right\}=1 .
$$

Hence, $\operatorname{Val}_{r}^{\beta}\left(\&_{B \in L} B\right)=1$ or $\operatorname{Val}_{r}^{\beta}\left(\&_{C \in M} C\right)$ $=1$, so, as before, $\operatorname{Con}\left(t^{\prime}, t^{\prime \prime}, L\right)=1$ or $\operatorname{Con}\left(t^{\prime}, t^{\prime \prime}, M\right)=1$.

If $\operatorname{Con}\left(t^{\prime}, t^{\prime \prime}, L\right)=1$, then, there exists $t^{\prime \prime \prime} \in r^{\prime}$, $t^{\prime \prime \prime}=t^{\prime \prime}$, such that $\left(t^{\prime \prime \prime}, t^{\prime}, t^{\prime \prime}, K, L, M, \theta_{2}, r^{\prime}\right)$ holds true.

If $C o n\left(t^{\prime}, t^{\prime \prime}, M\right)=1$, then, there exists $t^{\prime \prime \prime} \in r^{\prime}$, $t^{\prime \prime \prime}=t^{\prime}$, such that $\left(t^{\prime \prime \prime}, t^{\prime}, t^{\prime \prime}, K, L, M, \theta_{2}, r^{\prime}\right)$ holds true.

Suppose that

$h\left(\max \left\{\operatorname{Val}_{r}^{\beta}\left(\&_{B \in L} B\right), \operatorname{Val}_{r}^{\beta}\left(\&_{C \in M} C\right)\right\}\right)>0$.

We obtain,

$$
\begin{aligned}
& \frac{h\left(\frac{1}{2}\right)}{h\left(\max \left\{V_{a} l_{r}^{\beta}\left(\&_{B \in L} B\right), \operatorname{Val}_{r}^{\beta}\left(\&_{C \in M} C\right)\right\}\right)} \\
& >\operatorname{Val}_{r}^{\beta}\left(\&_{A \in K} A\right) .
\end{aligned}
$$

Since, $\operatorname{Val}_{r}^{\beta}\left(\&_{A \in K} A\right)>\frac{1}{2}$, it follows that

$$
\frac{h\left(\frac{1}{2}\right)}{h\left(\max \left\{\operatorname{Val}_{r}^{\beta}\left(\&_{B \in L} B\right), \operatorname{Val}_{r}^{\beta}\left(\&_{C \in M} C\right)\right\}\right)}>1,
$$

i.e.,

$$
\begin{aligned}
& h\left(\max \left\{\operatorname{Val}_{r}^{\beta}\left(\&_{B \in L} B\right), \operatorname{Val}_{r}^{\beta}\left(\&_{C \in M} C\right)\right\}\right) \\
< & h\left(\frac{1}{2}\right),
\end{aligned}
$$

i.e.,

$$
\max \left\{\operatorname{Val}_{r}^{\beta}\left(\&_{B \in L} B\right), \operatorname{Val}_{r}^{\beta}\left(\&_{C \in M} C\right)\right\}>\frac{1}{2} .
$$

Consequently, $\operatorname{Val}_{r}^{\beta}\left(\&_{B \in L} B\right)>\frac{1}{2}$ or $\operatorname{Val}_{r}^{\beta}\left(\&_{C \in M} C\right)>\frac{1}{2}$.

Hence, as in the case $\operatorname{Val}_{r}^{\beta}\left(\&_{B \in L} B\right)=1>$ $\frac{1}{2}$ or $\operatorname{Val}_{r}^{\beta}\left(\&_{C \in M} C\right)=1>\frac{1}{2}$, we conclude that $\left(t^{\prime \prime \prime}, t^{\prime}, t^{\prime \prime}, K, L, M, \theta_{2}, r^{\prime}\right)$ holds true.

Now, we prove that $r^{\prime}$ satisfies $\left(X, f, Y, \theta_{1}, F\right)$ resp. $\left(X, m, Y, \theta_{1}, F\right)$.

By our assumption, we have that $V a l_{r}^{\beta}\left(F_{X, Y}^{f}\right)$ $\leq \frac{1}{2}$ resp. $\operatorname{Val}_{r}^{\beta}\left(F_{X, Y}^{m}\right) \leq \frac{1}{2}$.

Reasoning in exactly the same way as above, we obtain that (1) resp. (2) holds true.

Without loss of generality, we may assume that (3) resp. (4) does not hold.

This actually means that (5) resp. (6) holds true. Hence, (7) resp. (8) holds true.

If $\operatorname{Val}_{r}^{\beta}\left(\&_{A \in X} A\right) \leq \frac{1}{2}$, then, (7) resp. (8) yields that

$$
\frac{h\left(\frac{1}{2}\right)}{h\left(\operatorname{Val}_{r}^{\beta}\left(\&_{B \in Y} B\right)\right)}=0
$$

resp.

$$
\begin{aligned}
& \frac{h\left(\frac{1}{2}\right)}{h\left(\max \left\{V a l_{r}^{\beta}\left(\&_{B \in Y} B\right), V a l_{r}^{\beta}\left(\&_{C \in Z} C\right)\right\}\right)} \\
= & 0,
\end{aligned}
$$

i.e., that $h\left(\frac{1}{2}\right)=0$.

This is a contradiction, however.

Consequently, $\operatorname{Val}_{r}^{\beta}\left(\&_{A \in X} A\right)>\frac{1}{2}$.

This fact, and (7) resp. (8) imply that

$$
\frac{h\left(\frac{1}{2}\right)}{h\left(\operatorname{Val}_{r}^{\beta}\left(\&_{B \in Y} B\right)\right)} \leq \frac{1}{2}(<1)
$$

resp.

$$
\begin{aligned}
& \frac{h\left(\frac{1}{2}\right)}{h\left(\max \left\{V a l_{r}^{\beta}\left(\&_{B \in Y} B\right), V a l_{r}^{\beta}\left(\&_{C \in Z} C\right)\right\}\right)} \\
& \leq \frac{1}{2}(<1),
\end{aligned}
$$


i.e.,

$$
\operatorname{Val}_{r}^{\beta}\left(\&_{B \in Y} B\right)<\frac{1}{2}
$$

resp.

$$
\max \left\{\operatorname{Val} l_{r}^{\beta}\left(\&_{B \in Y} B\right), \operatorname{Val}_{r}^{\beta}\left(\&_{C \in Z} C\right)\right\}<\frac{1}{2},
$$

i.e., $\operatorname{Val}_{r}^{\beta}\left(\&_{B \in Y} B\right)<\frac{1}{2}$ resp. $\operatorname{Val}_{r}^{\beta}\left(\&_{B \in Y} B\right)<\frac{1}{2}$, $\operatorname{Val}_{r}^{\beta}\left(\&_{C \in Z} C\right)<\frac{1}{2}$.

Now, in the fuzzy functional case, we have that $\operatorname{Val}_{r}^{\beta}\left(\&_{A \in X} A\right)>\frac{1}{2}, \operatorname{Val}_{r}^{\beta}\left(\&_{B \in Y} B\right)<\frac{1}{2}$, so $\operatorname{Con}\left(t^{\prime}, t^{\prime \prime}, X\right)=1, \operatorname{Con}\left(t^{\prime}, t^{\prime \prime}, Y\right)=\theta^{\prime \prime}$.

It follows that

$$
\begin{aligned}
& \operatorname{Con}\left(t^{\prime}, t^{\prime \prime}, Y\right) \\
= & \theta^{\prime \prime}<\theta^{\prime} \leq \theta_{1}=\min \left\{\theta_{1}, 1\right\} \\
= & \min \left\{\theta_{1}, \operatorname{Con}\left(t^{\prime}, t^{\prime \prime}, X\right)\right\} .
\end{aligned}
$$

In other words, $r^{\prime}$ violates $\left(X, f, Y, \theta_{1}, F\right)$. In the fuzzy multivalued case, we have that $\operatorname{Val}_{r}^{\beta}\left(\&_{A \in X} A\right)>\frac{1}{2}, \operatorname{Val}_{r}^{\beta}\left(\&_{B \in Y} B\right)<\frac{1}{2}$, and $\operatorname{Val} l_{r}^{\beta}\left(\&_{C \in Z} C\right)<\frac{1}{2}$, so $C o n\left(t^{\prime}, t^{\prime \prime}, X\right)=1$, $\operatorname{Con}\left(t^{\prime}, t^{\prime \prime}, Y\right)=\theta^{\prime \prime}$, and $\operatorname{Con}\left(t^{\prime}, t^{\prime \prime}, Z\right)=\theta^{\prime \prime}$.

Thus, if $t^{\prime \prime \prime} \in r^{\prime}, t^{\prime \prime \prime}=t^{\prime}$, then

$$
\begin{aligned}
& \operatorname{Con}\left(t^{\prime \prime \prime}, t^{\prime \prime}, Z\right) \\
= & \theta^{\prime \prime}<\theta^{\prime} \leq \theta_{1}=\min \left\{\theta_{1}, 1\right\} \\
= & \min \left\{\theta_{1}, \operatorname{Con}\left(t^{\prime}, t^{\prime \prime}, X\right)\right\} .
\end{aligned}
$$

Similarly, if $t^{\prime \prime \prime} \in r^{\prime}, t^{\prime \prime \prime}=t^{\prime \prime}$, then

$$
\begin{aligned}
& \operatorname{Con}\left(t^{\prime \prime \prime}, t^{\prime}, Y\right) \\
= & \theta^{\prime \prime}<\min \left\{\theta_{1}, \operatorname{Con}\left(t^{\prime}, t^{\prime \prime}, X\right)\right\} .
\end{aligned}
$$

These inequalities mean that $\left(t^{\prime \prime \prime}, t^{\prime}, t^{\prime \prime}, X, Y, Z, \theta_{1}, r^{\prime}\right)$ does not hold, i.e., that $r^{\prime}$ violates $\left(X, m, Y, \theta_{1}, F\right)$.

Now, suppose that $\operatorname{Val} l_{r}^{\beta}\left(c^{\prime}\right)>\frac{1}{2}$ for every valuation $\operatorname{Val}_{r}^{\beta}$, such that $\operatorname{Val}_{r}^{\beta}\left(F_{K, L}^{f}\right)>\frac{1}{2}$ and
$\operatorname{Val}_{r}^{\beta}\left(F_{K, L}^{m}\right)>\frac{1}{2}$ for all $F_{K, L}^{f} \in C^{\prime}$ and all $F_{K, L}^{m}$ $\in C^{\prime}$.

We shall prove that $\left(X, f, Y, \theta_{1}, F\right)$ resp. $\left(X, m, Y, \theta_{1}, F\right)$ is satisfied by $r$ if $\left(K, f, L, \theta_{2}, F\right)$ is satisfied by $r$, and $\left(K, m, L, \theta_{2}, F\right)$ is satisfied by $r$, for all $\left(K, f, L, \theta_{2}, F\right) \in C$ and all $\left(K, m, L, \theta_{2}, F\right)$ $\in C$, where $r$ is a two-element fuzzy relation instance on given scheme $\operatorname{Sch}\left(A_{1}, A_{2}, \ldots, A_{n}\right)$.

Suppose that the last statement is not satisfied.

This means that there exists some $r^{\prime}=$ $\left\{t^{\prime}, t^{\prime \prime}\right\}$, such that $\left(K, f, L, \theta_{2}, F\right)$ is satisfied by $r^{\prime}$, and $\left(K, m, L, \theta_{2}, F\right)$ is satisfied by $r^{\prime}$, for all $\left(K, f, L, \theta_{2}, F\right) \in C$, and all $\left(K, m, L, \theta_{2}, F\right) \in C$, but $\left(X, f, Y, \theta_{1}, F\right)$ resp. $\left(X, m, Y, \theta_{1}, F\right)$ is not satisfied by $r^{\prime}$.

Denote by $Z^{\prime}$ the set

$$
\left\{A \in\left\{A_{1}, A_{2}, \ldots, A_{n}\right\}: \operatorname{Con}\left(t^{\prime}, t^{\prime \prime}, A\right)=1\right\}
$$

First, suppose that $Z^{\prime}=\emptyset$.

It follows that $\operatorname{Con}\left(t^{\prime}, t^{\prime \prime}, A\right)=\theta^{\prime \prime}$ for all $A \in$ $\left\{A_{1}, A_{2}, \ldots, A_{n}\right\}$.

Thus,

$$
\begin{aligned}
& \operatorname{Con}\left(t^{\prime}, t^{\prime \prime}, Q\right) \\
= & \min \left\{\operatorname{Con}\left(t^{\prime}, t^{\prime \prime}, A\right): A \in Q\right\}=\theta^{\prime \prime}
\end{aligned}
$$

for any $Q \subseteq\left\{A_{1}, A_{2}, \ldots, A_{n}\right\}$.

By our assumption, $\left(X, f, Y, \theta_{1}, F\right)$ resp.

$\left(X, m, Y, \theta_{1}, F\right)$ is not satisfied by $r^{\prime}$, i.e., $\left(t^{\prime}, t^{\prime \prime}, Y, \theta_{1}, X, r^{\prime}\right)$ resp. $\left(t^{\prime \prime \prime}, t^{\prime}, t^{\prime \prime}, X, Y, Z, \theta_{1}, r^{\prime}\right)$ does not hold.

Note that $\operatorname{Con}\left(t^{\prime}, t^{\prime \prime}, X\right)=\theta^{\prime \prime}, \operatorname{Con}\left(t^{\prime}, t^{\prime \prime}, Y\right)$ $=\theta^{\prime \prime}$, and $\operatorname{Con}\left(t^{\prime}, t^{\prime \prime}, Z\right)=\theta^{\prime \prime}$.

So, the fact that $\left(t^{\prime}, t^{\prime \prime}, Y, \theta_{1}, X, r^{\prime}\right)$ does not hold, yields a contradiction since $\min \left\{\theta_{1}, \theta^{\prime \prime}\right\}=\theta^{\prime \prime}$.

Similarly, $\left(t^{\prime \prime \prime}, t^{\prime}, t^{\prime \prime}, X, Y, Z, \theta_{1}, r^{\prime}\right)$ does not hold, so, in particular, $\left(t^{\prime}, t^{\prime}, t^{\prime \prime}, X, Y, Z, \theta_{1}, r^{\prime}\right)$ does not hold.

This is a contradiction, since, once again

$$
\theta^{\prime \prime}=\min \left\{\theta_{1}, \theta^{\prime \prime}\right\}=\min \left\{\theta_{1}, \operatorname{Con}\left(t^{\prime}, t^{\prime \prime}, X\right)\right\}
$$


Since the assumption $Z^{\prime}=\emptyset$ yields to contradiction, it follows that $Z^{\prime} \neq \emptyset$.

Second, suppose that $Z^{\prime}=\left\{A_{1}, A_{2}, \ldots, A_{n}\right\}$.

It follows that $\operatorname{Con}\left(t^{\prime}, t^{\prime \prime}, A\right)=1$ for all $A \in$ $\left\{A_{1}, A_{2}, \ldots, A_{n}\right\}$.

Thus,

$$
\begin{aligned}
& \operatorname{Con}\left(t^{\prime}, t^{\prime \prime}, Q\right) \\
= & \min \left\{\operatorname{Con}\left(t^{\prime}, t^{\prime \prime}, A\right): A \in Q\right\}=1
\end{aligned}
$$

for any $Q \subseteq\left\{A_{1}, A_{2}, \ldots, A_{n}\right\}$.

Now, $C$ on $\left(t^{\prime}, t^{\prime \prime}, X\right)=1, \operatorname{Con}\left(t^{\prime}, t^{\prime \prime}, Y\right)=1$, and $C o n\left(t^{\prime}, t^{\prime \prime}, Z\right)=1$.

Since $\left(X, f, Y, \theta_{1}, F\right)$ is not satisfied by $r^{\prime}$, we have that 1 is strictly smaller than $\min \left\{\theta_{1}, 1\right\}=\theta_{1}$.

This is a contradiction.

Similarly, $\left(X, m, Y, \theta_{1}, F\right)$ is not satisfied by $r^{\prime}$, so $\left(t^{\prime \prime \prime}, t^{\prime}, t^{\prime \prime}, X, Y, Z, \theta_{1}, r^{\prime}\right)$ does not hold, and then $\left(t^{\prime}, t^{\prime}, t^{\prime \prime}, X, Y, Z, \theta_{1}, r^{\prime}\right)$ does not hold.

We obtain that 1 is strictly smaller than

$$
\theta_{1}=\min \left\{\theta_{1}, 1\right\}=\min \left\{\theta_{1}, \operatorname{Con}\left(t^{\prime}, t^{\prime \prime}, X\right)\right\}
$$

Hence, a contradiction.

So, the assumption that $Z^{\prime}=\left\{A_{1}, A_{2}, \ldots, A_{n}\right\}$ yields a contradiction.

It follows that $Z^{\prime} \subset\left\{A_{1}, A_{2}, \ldots, A_{n}\right\}$.

We have, $\emptyset \neq Z^{\prime} \subset\left\{A_{1}, A_{2}, \ldots, A_{n}\right\}$. $\mathrm{Val}_{r^{\prime}}^{1}$

In the sequel, we shall consider the valuation

We shall prove that $V a l_{r^{\prime}}^{1}\left(F_{K, L}^{f}\right)>\frac{1}{2}$ and $\operatorname{Val}_{r^{\prime}}^{1}\left(F_{K, L}^{m}\right)>\frac{1}{2}$ for all $F_{K, L}^{f} \in C^{\prime}$ and all $F_{K, L}^{m} \in$ $C^{\prime}$, but $V a l_{r^{\prime}}^{1}\left(c^{\prime}\right) \leq \frac{1}{2}$.

Let $F_{K, L}^{f} \in C^{\prime}$.

Suppose that $\operatorname{Val}_{r^{\prime}}^{1}\left(F_{K, L}^{f}\right) \leq \frac{1}{2}$ resp. $\operatorname{Val}_{r^{\prime}}^{1}\left(F_{K, L}^{m}\right) \leq \frac{1}{2}$.

We obtain,

$$
\begin{aligned}
& V a l_{r^{\prime}}^{1}\left(\left(\&_{A \in K} A\right) \rightarrow\left(\&_{B \in L} B\right)\right) \\
= & h^{-1}\left(\operatorname { m a x } \left\{V a l_{r^{\prime}}^{1},\left(\&_{A \in K} A\right) \times\right.\right. \\
& \left.\left.\times h\left(\operatorname{Val}_{r^{\prime}}^{1}\left(\&_{B \in L} B\right)\right), h(1)\right\}\right)
\end{aligned}
$$

$$
\leq \frac{1}{2}
$$

resp.

$$
\begin{aligned}
& \operatorname{Val}_{r^{\prime}}^{1}\left(\left(\&_{A \in K} A\right) \rightarrow\left(\left(\&_{B \in L} B\right) \|\left(\&_{C \in M} C\right)\right)\right) \\
= & h^{-1}\left(\operatorname { m a x } \left\{V a l_{r^{\prime}}^{1}\left(\&_{A \in K} A\right) \times\right.\right. \\
& \times h\left(\max \left\{V a l_{r^{\prime}}^{1}\left(\&_{B \in L} B\right), V a l_{r^{\prime}}^{1}\left(\&_{C \in M} C\right)\right\}\right) \\
& , h(1)\}) \\
\leq & \frac{1}{2}
\end{aligned}
$$

i.e.,

$$
\begin{aligned}
& \max \left\{\operatorname{Val}_{r^{\prime}}^{1}\left(\&_{A \in K} A\right) \times\right. \\
& \left.\times h\left(\operatorname{Val}_{r^{\prime}}^{1}\left(\&_{B \in L} B\right)\right), h(1)\right\} \geq h\left(\frac{1}{2}\right)
\end{aligned}
$$

resp.

$$
\begin{aligned}
& \max \left\{\operatorname{Val}_{r^{\prime}}^{1}\left(\&_{A \in K} A\right) \times\right. \\
& \times h\left(\max \left\{\operatorname{Val}_{r^{\prime}}^{1}\left(\&_{B \in L} B\right), \operatorname{Val}_{r^{\prime}}^{1}\left(\&_{C \in M} C\right)\right\}\right) \\
& , h(1)\} \geq h\left(\frac{1}{2}\right) .
\end{aligned}
$$

The fact that $\frac{1}{2}<1$, implies that $h\left(\frac{1}{2}\right)>h(1)$. Therefore,

$$
\begin{aligned}
& V_{a l}^{1}{r^{\prime}}^{\prime}\left(\&_{A \in K} A\right) h\left(\operatorname{Val}_{r^{\prime}}^{1}\left(\&_{B \in L} B\right)\right) \\
= & \max \left\{V a l_{r^{\prime}}^{1}\left(\&_{A \in K} A\right) \times\right. \\
& \left.\times h\left(V a l_{r^{\prime}}^{1}\left(\&_{B \in L} B\right)\right), h(1)\right\} \geq h\left(\frac{1}{2}\right)
\end{aligned}
$$

resp.

$$
\begin{aligned}
& V a l_{r^{\prime}}^{1}\left(\&_{A \in K} A\right) h\left(\operatorname { m a x } \left\{V a l_{r^{\prime}}^{1}\left(\&_{B \in L} B\right),\right.\right. \\
& \left.\left.V a l_{r^{\prime}}^{1}\left(\&_{C \in M} C\right)\right\}\right) \geq h\left(\frac{1}{2}\right) .
\end{aligned}
$$


We may assume, without loss of generality, that

$$
h\left(\operatorname{Val}_{r^{\prime}}^{1}\left(\&_{B \in L} B\right)\right)>0
$$

resp.

$$
\begin{aligned}
& h\left(\operatorname { m a x } \left\{V a l_{r^{\prime}}^{1}\left(\&_{B \in L} B\right),\right.\right. \\
& \left.\left.V a l_{r^{\prime}}^{1}\left(\&_{C \in M} C\right)\right\}\right)>0 .
\end{aligned}
$$

If $\operatorname{Val}_{r^{\prime}}^{1}\left(\&_{A \in K} A\right) \leq \frac{1}{2}$, then $\operatorname{Con}\left(t^{\prime}, t^{\prime \prime}, K\right)=$ $\theta^{\prime \prime}$, and (9) resp. (10) implies that

$$
\frac{h\left(\frac{1}{2}\right)}{h\left(\operatorname{Val}_{r^{\prime}}^{1}\left(\&_{B \in L} B\right)\right)}=0
$$

resp.

$$
\begin{aligned}
& h\left(\max \left\{\operatorname{Val}_{r^{\prime}}^{1}\left(\&_{B \in L} B\right), V a l_{r^{\prime}}^{1}\left(\&_{C \in M} C\right)\right\}\right) \\
& =0,
\end{aligned}
$$

i.e., that $h\left(\frac{1}{2}\right)=0$.

This is contradiction, however.

Consequently, $\operatorname{Val}_{r^{\prime}}^{1}\left(\&_{A \in K} A\right)>\frac{1}{2}$, so Con $\left(t^{\prime}, t^{\prime \prime}, K\right)=1$, and (9) resp. (10) yields that

$$
V a l_{r^{\prime}}^{1}\left(\&_{B \in L} B\right)<\frac{1}{2}
$$

resp.

$$
\max \left\{V a l_{r^{\prime}}^{1}\left(\&_{B \in L} B\right), V a l_{r^{\prime}}^{1}\left(\&_{C \in M} C\right)\right\}<\frac{1}{2},
$$

i.e., that $\operatorname{Con}\left(t^{\prime}, t^{\prime \prime}, L\right)=\theta^{\prime \prime}$ resp. $\operatorname{Con}\left(t^{\prime}, t^{\prime \prime}, L\right)$ $=\theta^{\prime \prime}, C o n\left(t^{\prime}, t^{\prime \prime}, M\right)=\theta^{\prime \prime}$.

Since $\left(K, f, L, \theta_{2}, F\right)$ is satisfied by $r^{\prime}$ for all $\left(K, f, L, \theta_{2}, F\right) \in C$, we obtain a contradiction that $\theta_{2}=\min \left\{\theta_{2}, 1\right\}$ is not larger than $\theta^{\prime \prime}$.

Moreover, by our assumption, $\left(K, m, L, \theta_{2}, F\right)$ is satisfied by $r^{\prime}$ for all $\left(K, m, L, \theta_{2}, F\right) \in C$.

This means that $\left(t^{\prime \prime \prime}, t^{\prime}, t^{\prime \prime}, K, L, M, \theta_{2}, r^{\prime}\right)$ holds true for some $t^{\prime \prime \prime} \in r^{\prime}$.
This, however, is not possible since we have that $\theta_{2}=\min \left\{\theta_{2}, 1\right\}$ is larger that $\theta^{\prime \prime}$.

Hence, a contradiction.

Thus, our assumption that $\operatorname{Val}_{r^{\prime}}^{1}\left(F_{K, L}^{f}\right) \leq \frac{1}{2}$ resp. $\operatorname{Val}_{r^{\prime}}^{1}\left(F_{K, L}^{m}\right) \leq \frac{1}{2}$ is not valid.

Therefore, $V a l_{r^{\prime}}^{1}\left(F_{K, L}^{f}\right)>\frac{1}{2}$ and $V a l_{r^{\prime}}^{1}\left(F_{K, L}^{m}\right)$ $>\frac{1}{2}$ for all $F_{K, L}^{f} \in C^{\prime}$ and all $F_{K, L}^{m} \in C^{\prime}$.

Finally, we prove that $V a l_{r^{\prime}}^{1}\left(c^{\prime}\right) \leq \frac{1}{2}$, i.e., that $\operatorname{Val}_{r^{\prime}}^{1}\left(F_{X, Y}^{f}\right) \leq \frac{1}{2}$ resp. $\operatorname{Val}_{r^{\prime}}^{1}\left(F_{X, Y}^{m}\right) \leq \frac{1}{2}$.

Suppose that $\operatorname{Val}_{r^{\prime}}^{1}\left(F_{X, Y}^{f}\right)>\frac{1}{2}$ resp. $\operatorname{Val}_{r^{\prime}}^{1}\left(F_{X, Y}^{m}\right)>\frac{1}{2}$.

Reasoning in the same way as in the case $\operatorname{Val}_{r}^{\beta}\left(F_{K, L}^{f}\right)>\frac{1}{2}$ resp. $\operatorname{Val}_{r}^{\beta}\left(F_{K, L}^{m}\right)>\frac{1}{2}$, we obtain that

$$
\begin{aligned}
& \operatorname{Val}_{r^{\prime}}^{1}\left(\&_{A \in X} A\right) h\left(\operatorname{Val}_{r^{\prime}}^{1}\left(\&_{B \in Y} B\right)\right) \\
< & h\left(\frac{1}{2}\right)
\end{aligned}
$$

resp.

$$
\begin{aligned}
& \operatorname{Val}_{r^{\prime}}^{1}\left(\&_{A \in X} A\right) \times \\
& \times h\left(\operatorname { m a x } \left\{V a l_{r^{\prime}}^{1}\left(\&_{B \in Y} B\right),\right.\right. \\
& \left.\left.\operatorname{Val}_{r^{\prime}}^{1}\left(\&_{C \in Z} C\right)\right\}\right)<h\left(\frac{1}{2}\right) .
\end{aligned}
$$

Note that by our assumption, $\left(X, f, Y, \theta_{1}, F\right)$ resp. $\left(X, m, Y, \theta_{1}, F\right)$ is not satisfied by $r^{\prime}$, i.e., $\left(t^{\prime}, t^{\prime \prime}, Y, \theta_{1}, X, r^{\prime}\right)$ resp. $\left(t^{\prime \prime \prime}, t^{\prime}, t^{\prime \prime}, X, Y, Z, \theta_{1}, r^{\prime}\right)$ does not hold.

Without loss of generality, we shall assume that

$$
h\left(\operatorname{Val}_{r^{\prime}}^{1}\left(\&_{B \in Y} B\right)\right)>0
$$

resp.

$h\left(\max \left\{V a l_{r^{\prime}}^{1}\left(\&_{B \in Y} B\right), V a l_{r^{\prime}}^{1}\left(\&_{C \in Z} C\right)\right\}\right)>0$. $\theta^{\prime \prime}$. 
Since $C o n\left(t^{\prime}, t^{\prime \prime}, Q\right) \geq \theta^{\prime \prime}$ for any $Q \subseteq$ $\left\{A_{1}, A_{2}, \ldots, A_{n}\right\}$, it follows that $\operatorname{Con}\left(t^{\prime}, t^{\prime \prime}, Y\right) \geq$ $\theta^{\prime \prime}$.

Moreover, $\min \left\{\theta_{1}, \theta^{\prime \prime}\right\}=\theta^{\prime \prime}$.

This contradicts the fact that $\left(t^{\prime}, t^{\prime \prime}, Y, \theta_{1}, X, r^{\prime}\right)$ does not hold.

On the other side, in the fuzzy multivalued case, we obtain that $\left(t^{\prime}, t^{\prime}, t^{\prime \prime}, X, Y, Z, \theta_{1}, r^{\prime}\right)$ holds true.

This contradicts the fact that $\left(t^{\prime \prime \prime}, t^{\prime}, t^{\prime \prime}, X, Y, Z, \theta_{1}, r^{\prime}\right)$ does not hold.

We conclude, $\operatorname{Val}_{r^{\prime}}^{1}\left(\&_{A \in X} A\right)>\frac{1}{2}$.

Hence, $C o n\left(t^{\prime}, t^{\prime \prime}, X\right)=1$, and (11) resp. (12) yields that

$$
h\left(V a l_{r^{\prime}}^{1}\left(\&_{B \in Y} B\right)\right)<h\left(\frac{1}{2}\right)
$$

resp.

$$
\begin{aligned}
& h\left(\max \left\{V a l_{r^{\prime}}^{1}\left(\&_{B \in Y} B\right), V a l_{r^{\prime}}^{1}\left(\&_{C \in Z} C\right)\right\}\right) \\
< & h\left(\frac{1}{2}\right)
\end{aligned}
$$

i.e., that $\operatorname{Val}_{r^{\prime}}^{1}\left(\&_{B \in Y} B\right)>\frac{1}{2}$ resp. $\operatorname{Val}_{r^{\prime}}^{1}\left(\&_{B \in Y} B\right)$ $>\frac{1}{2}$ or $\operatorname{Val}_{r^{\prime}}^{1}\left(\&_{C \in Z} C\right)>\frac{1}{2}$.

It follows that $C$ on $\left(t^{\prime}, t^{\prime \prime}, Y\right)=1$ resp. $\operatorname{Con}\left(t^{\prime}, t^{\prime \prime}, Y\right)=1$ or $\operatorname{Con}\left(t^{\prime}, t^{\prime \prime}, Z\right)=1$.

Since $C o n\left(t^{\prime}, t^{\prime \prime}, Y\right)=1$, we obtain a contradiction in the fuzzy functional case with the fact that $\left(t^{\prime}, t^{\prime \prime}, Y, \theta_{1}, X, r^{\prime}\right)$ does not hold.

In the fuzzy multivalued case, we have that $\operatorname{Con}\left(t^{\prime}, t^{\prime \prime}, X\right)=1, \operatorname{Con}\left(t^{\prime}, t^{\prime \prime}, Y\right)=1$ or $\operatorname{Con}\left(t^{\prime}, t^{\prime \prime}, X\right)=1, \operatorname{Con}\left(t^{\prime}, t^{\prime \prime}, Z\right)=1$.

In the first case we obtain that $\left(t^{\prime \prime}, t^{\prime}, t^{\prime \prime}, X, Y, Z, \theta_{1}, r^{\prime}\right)$ holds true, while in the second case, we obtain that $\left(t^{\prime}, t^{\prime}, t^{\prime \prime}, X, Y, Z, \theta_{1}, r^{\prime}\right)$ holds true.

This contradicts the fact that $\left(t^{\prime \prime \prime}, t^{\prime}, t^{\prime \prime}, X, Y, Z, \theta_{1}, r^{\prime}\right)$ does not hold.

Therefore, $V a l_{r^{\prime}}^{1}\left(F_{X, Y}^{f}\right) \leq \frac{1}{2}$ resp. $\operatorname{Val}_{r^{\prime}}^{1}\left(F_{X, Y}^{m}\right) \leq \frac{1}{2}$.
This contradicts our assumption that $\operatorname{Val}_{r}^{\beta}\left(F_{X, Y}^{f}\right)>\frac{1}{2}$ resp. $\operatorname{Val}_{r}^{\beta}\left(F_{X, Y}^{m}\right)>\frac{1}{2}$ for every valuation $V a l_{r}^{\beta}$, such that $\operatorname{Val}_{r}^{\beta}\left(F_{K, L}^{f}\right)>\frac{1}{2}$ and $\operatorname{Val}_{r}^{\beta}\left(F_{K, L}^{m}\right)>\frac{1}{2}$ for all $F_{K, L}^{f} \in C^{\prime}$ and all $F_{K, L}^{m} \in$ $C^{\prime}$

This means that our assumption on $r^{\prime}$ is not valid.

Consequently, $\left(X, f, Y, \theta_{1}, F\right)$ resp.

$\left(X, m, Y, \theta_{1}, F\right)$ is satisfied by $r$ if $\left(K, f, L, \theta_{2}, F\right)$ is satisfied by $r$, and $\left(K, m, L, \theta_{2}, F\right)$ is satisfied by $r$ for all $\left(K, f, L, \theta_{2}, F\right) \in C$ and all $\left(K, m, L, \theta_{2}, F\right)$ $\in C$, where $r$ is a two-element fuzzy relation instance on $\operatorname{Sch}\left(A_{1}, A_{2}, \ldots, A_{n}\right)$.

\section{Concluding remarks}

In order to complement the notation applied in the previous section, we note the following.

We say that $(X, f, Y, \theta, V)$ is satisfied by $r(r$ is arbitrary vague relation instance on $\left.\operatorname{Sch}\left(A_{1}, A_{2}, \ldots, A_{n}\right)\right)$, if for $t_{1}, t_{2} \in r$,

$$
\operatorname{Con}\left(t_{1}, t_{2}, Y\right) \geq \min \left\{\theta, \operatorname{Con}\left(t_{1}, t_{2}, X\right)\right\} .
$$

We also say that $\left(t_{1}, t_{2}, Y, \theta_{1}, X, r\right)$ holds true (see, [16, p. 6]).

Furthermore, we say that $(X, m, Y, \theta, V)$ is satisfied by $r$ ( $r$ is arbitrary), if for $t_{1}, t_{2} \in r$, there is $t_{3} \in$ $r$, such that

$$
\begin{aligned}
& C o n\left(t_{3}, t_{1}, X\right) \geq \min \left\{\theta, \text { Con }\left(t_{1}, t_{2}, X\right)\right\}, \\
& \operatorname{Con}\left(t_{3}, t_{1}, Y\right) \geq \min \left\{\theta, \text { Con }\left(t_{1}, t_{2}, X\right)\right\}, \\
& \operatorname{Con}\left(t_{3}, t_{2}, Z\right) \geq \min \left\{\theta, \text { Con }\left(t_{1}, t_{2}, X\right)\right\} .
\end{aligned}
$$

As in the case of fuzzy multivalued dependencies, we say that $\left(t_{3}, t_{1}, t_{2}, X, Y, Z, \theta, r\right)$ holds true (see, $[17$, p. 5]).

The concept of conformance is introduced by Definitions 3.1 and 3.2 in [15, pp. 165-166], and is applied further on in [23], and also adapted in [16] and [17].

In any case, it is based on application of appropriate similarity relation.

In this and similar researches, is is usually comfortable to select a general similarity relation which is reflexive, symmetric, and satisfies the max-min transitivity condition (this definition is quite restrictive, but also possible to occur in reality). 
However, in the vague functional case, the authors are more relaxed during such selection [24], [25], [26].

Furthermore, the concept of valuation (or an interpretation) is adopted from [27], and adapted to our setting.

In short, it enables us to translate the attributes into fuzzy formulas.

Depending on the fact that $\operatorname{Con}\left(t_{1}, t_{2}, A\right)$ is larger resp. smaller than some fixed value $\beta \in[0,1]$, we define the corresponding valuation value $\operatorname{Val}_{r}^{\beta}(A)$ $>\frac{1}{2}$ resp. $<\frac{1}{2}$, with $r=\left\{t_{1}, t_{2}\right\}$.

As it can be seen from the previous section, we assume that the fuzzy conjunction operator is modeled by the minimum $t$-norm [28, p. 17].

Furthermore, the fuzzy disjunction is modeled by the maximum $t$-conorm [28, p. 23] (see also, [29]).

The results derived in the previous section may be formulated in the following form.

Theorem 1. Let $I_{h}$ be an $h$-generated implication, and $(X, m, Y, \theta, F)$ resp. (X, $m, Y, \theta, V)$ fuzzy resp. vague multivalued dependency on

$\operatorname{Sch}\left(A_{1}, A_{2}, \ldots, A_{n}\right)$. Then, $\left(t_{3}, t_{1}, t_{2}, X, Y, Z, \theta, r\right)$ holds true and $C o n\left(t_{1}, t_{2}, A\right) \geq \theta$ for all $A \in X$ if and only if $\operatorname{Con}\left(t_{1}, t_{2}, X\right) \geq \theta$ and $\operatorname{Val} l_{r}^{\theta}\left(F_{X, Y}^{m}\right)>$ $\frac{1}{2}$, where $r=\left\{t_{1}, t_{2}\right\}$.

Theorem 2. Let $I_{h}$ be an $h$-generated implication, and $\left(X, f, Y, \theta_{1}, F\right)\left(\left(X, f, Y, \theta_{1}, V\right)\right)$

resp. $\left(X, m, Y, \theta_{1}, F\right)\left(\left(X, m, Y, \theta_{1}, V\right)\right)$ fuzzy

(vague) functional resp. fuzzy (vague) multivalued dependency on $S c h\left(A_{1}, A_{2}, \ldots, A_{n}\right)$. Then,

$\left(t_{1}, t_{2}, Y, \theta_{1}, X, r\right)$ resp. $\left(t_{3}, t_{1}, t_{2}, X, Y, Z, \theta_{1}, r\right)$

holds true if $\left(t_{1}, t_{2}, L, \theta_{2}, K, r\right)$ and

$\left(t_{3}, t_{1}, t_{2}, K, L, M, \theta_{2}, r\right)$ hold true for all

$\left(K, f, L, \theta_{2}, F\right)\left(\left(K, f, L, \theta_{2}, V\right)\right), \quad\left(K, m, L, \theta_{2}, F\right)$ $\left(\left(K, m, L, \theta_{2}, V\right)\right) \in C$, where $r=\left\{t_{1}, t_{2}\right\}$, if and only if $\operatorname{Val}_{r}^{\beta}\left(F_{X, Y}^{f}\right)>\frac{1}{2}$ resp. $\operatorname{Val}_{r}^{\beta}\left(F_{X, Y}^{m}\right)>\frac{1}{2}$ for every valuation $V a l_{r}^{\beta}$, such that $\operatorname{Val}_{r}^{\beta}\left(F_{K, L}^{f}\right)>$ $\frac{1}{2}$ and $\operatorname{Val}_{r}^{\beta}\left(F_{K, L}^{m}\right)>\frac{1}{2}$ for all $F_{K, L}^{f} \in C^{\prime}$ and all $F_{K, L}^{m} \in C^{\prime}$.

Clearly, in Theorem 2, $C$ denotes the set of fuzzy (vague) functional and fuzzy (vague) multivalued dependencies on $S c h\left(A_{1}, A_{2}, \ldots, A_{n}\right)$, while $C^{\prime}$ denotes the corresponding set of fuzzy formulas.

Theorems 1 and 2 are derived for an $h$-generated implication.
By [30, p. 179, Th. 13], $I_{h}$ is an $(S, N)$ - implication, where $h$ is an $h$-generator, $S$ is some $t$-conorm, and $N$ is contiuous negation.

Moreover, by Corollaries 2 and 3 in [30], $I_{h}$ is an $(S, N)$-implication generated from some $t$-conorm and some strict (strong) negation if and only if $h(1)$ $=0\left(h=h^{-1}\right)$.

Taking into account these facts, it would be natural to try to verify the aforementioned results for various individual definitions of $S$-implications, such as Kleene-Dienes, Reichenbach, Most Strict, Largest, Least Strict, Lukasiewicz implication, etc., or, generally, for entire family of $S$-implications. These ideas may be regarded as the instructions for possible future work. Regarding the limitations of this study and suggested improvements of the work, we highlight that the limiting case for the future directions would be the case of the general fuzzy implication operator definition.

Note that the results given by Theorems 1 and 2 may be applied in the way described in [21] and [20].

\section{Applications}

We demonstrate the practical and the engineering applications of this study by the following example.

Example 1. Consider the fuzzy (vague) functional dependencies $\left(\{A, B\}, f, C, \theta_{1}, F(V)\right)$ and $\left(\{A, B\}, f, D, \theta_{2}, F(V)\right)$. We shall prove that these two dependencies imply the fuzzy (vague) functional dependency $(\{A, B\}, f,\{C, D\}, \theta, F(V))$, where $\theta=\min \left\{\theta_{1}, \theta_{2}\right\}$.

Here, we assume that the dependencies are given on some scheme $\operatorname{Sch}(A, B, C, D)$, where, clearly, $\{A, B\},\{C\},\{D\}$ and $\{C, D\}$ are subsets of the universal set of attributes $\{A, B, C, D\}$.

Of course, one way to derive $(\{A, B\}, f,\{C, D\}, \theta, F(V))$ is to derive it by hand. The augmentation rule for fuzzy (vague) functional dependencies states that the fuzzy (vague) functional dependency $(X, f, Y, \theta, F(V))$ yields the fuzzy (vague) functional dependency $(X \cup Z, f, Y \cup Z, \theta, F(V))$ for any subset $Z \subseteq$ $\{A, B, C, D\}$. Moreover, the transitivity rule for fuzzy (vague) functional dependencies says that the fuzzy (vague) functional dependencies $\left(X, f, Y, \theta_{1}, F(V)\right)$ and $\left(Y, f, Z, \theta_{2}, F(V)\right)$ imply the fuzzy (vague) functional dependency $(X, f, Z, \theta, F(V))$, where $\theta=\min \left\{\theta_{1}, \theta_{2}\right\}$. Thus, by assumption, $\left(\{A, B\}, f, C, \theta_{1}, F(V)\right)$ holds true. The augmentation with $\{A, B\}$ gives us the dependency $\left(\{A, B\}, f,\{A, B, C\}, \theta_{1}, F(V)\right)$. If we augment the dependency 
$\left(\{A, B\}, f, D, \theta_{2}, F(V)\right)$ with $\{C\}$, we obtain the dependency $\left(\{A, B, C\}, f,\{C, D\}, \theta_{2}, F(V)\right)$.

Now, the transitivity rule applied on

$\left(\{A, B\}, f,\{A, B, C\}, \theta_{1}, F(V)\right)$ and $\left(\{A, B, C\}, f,\{C, D\}, \theta_{2}, F(V)\right)$ gives us the dependency $(\{A, B\}, f,\{C, D\}, \theta, F(V))$. This completes our proof by hand, that is, the proof obtained by applying purely theoretical ingredients. This proof shows that deriving of new dependencies in this, classical way is not guaranteed to be easy task. It can be easy, of course. On the other side, it can also be very hard task to be done. Having in mind these facts, it is not so hard to conclude that this approach is not a reliable one.

On the other hand, we may apply Theorem 2 to obtain the dependency $(\{A, B\}, f,\{C, D\}, \theta, F(V))$. Indeed, suppose that $r,|r|=2$ is a fuzzy (vague) relation instance on $\operatorname{Sch}(A, B, C, D)$. Let $\beta \in[0,1]$ be some number. Furthermore, suppose that $\operatorname{Val}_{r}^{\beta}\left(F_{\{A, B\}, C}^{f}\right)=\operatorname{Val}_{r}^{\beta}((A \wedge B) \Rightarrow C)>$ $\frac{1}{2}, \operatorname{Val}_{r}^{\beta}\left(F_{\{A, B\}, D}^{f}\right)=\operatorname{Val}_{r}^{\beta}((A \wedge B) \Rightarrow D)>$ $\frac{1}{2}$. If we prove that $\operatorname{Val}_{r}^{\beta}\left(F_{\{A, B\},\{C, D\}}^{f}\right)=$ $\operatorname{Val}_{r}^{\beta}((A \wedge B) \Rightarrow(C \wedge D))>\frac{1}{2}$, then, in the view of Theorem 2, we shall immediately have that the dependency $(\{A, B\}, f,\{C, D\}, \theta, F(V))$ follows. In order to prove that $\operatorname{Val}_{r}^{\beta}\left(F_{\{A, B\},\{C, D\}}^{f}\right)>$ $\frac{1}{2}$ is satisfied, we assume the opposite, that $\operatorname{Val} l_{r}^{\beta}\left(F_{\{A, B\},\{C, D\}}^{f}\right) \leq \frac{1}{2}$ is valid. In other words, we assume that the fuzzy formulas $(A \wedge B) \Rightarrow C$, $(A \wedge B) \Rightarrow D$ and $\neg((A \wedge B) \Rightarrow(C \wedge D))$ hold true. Since $p \Rightarrow q \equiv \neg p \vee q$ for any $p$ and $q$, it follows that $\neg A \vee \neg B \vee C, \neg A \vee \neg B \vee D$, and $A \wedge B \wedge(\neg C \vee \neg D)$ hold true. In order to obtain a contradiction, we apply the resolution principle to the conjunctive terms $\neg A \vee \neg B \vee C, \neg A \vee \neg B \vee$ $D, A, B$ and $\neg C \vee \neg D$ of the derived fuzzy formulas. Thus, resolving $\neg A \vee \neg B \vee C$ by $A$ and then by $B$, we obtain $C$. Resolving $\neg A \vee \neg B \vee D$ by $A$ and then by $B$, we obtain $D$. Finally, resolving $\neg C \vee$ $\neg D$ by $C$ and then by $D$, we obtain a contradiction. Hence, $\operatorname{Val}_{r}^{\beta}\left(F_{\{A, B\},\{C, D\}}^{f}\right)>\frac{1}{2}$, so the dependency $(\{A, B\}, f,\{C, D\}, \theta, F(V))$ holds true. Note that the second proof may take more time to be done, but is also more reliable one. Namely, it always gives a solution, and it allows to be completely automated.

\section{Discussion}

Recall that the authors in [15] resp. [16], [17] first introduced the definitions of fuzzy functional and multivalued resp. vague functional and multivalued dependencies on the basis of conformance between attributes. With addition of the paper [18], the inference rules are listed, and are shown to be sound and complete. Based on these results, the authors in [23] proved that the set of the inference rules for fuzzy functional and fuzzy multivalued dependencies is complete set in two-element fuzzy relation instances (Theorem 7), and then, in general, in arbitrary fuzzy relation instances (Corollary 8). The corresponding results in vague setting are then derived in [19], [20], [21] and [22]. The completeness in arbitrary relations enabled the authors to leave the classical approach and its disadvantages during the process of derivation of new dependencies, and to automate the process by applying the resolution principle (see, [23], [20], [21]). The advantages of the automated approach are clearly demonstrated by Example 1. On the other side, the disadvantages of the classical approach are more than obvious: large number of inference rules, matter of their choice, unknown number of steps, uncertainty of outcome, etc. In order to obtain the completeness in arbitrary relations, the authors applied a number of various fuzzy implication operators, like: Kleene-Dienes, Reichenbach (Kleene-Dienes-Lukasiewicz), Yager, $f$-generated, $g$ generated, Lukasiewicz, Klir-Yuan [31], etc. In this paper we use the $h$-generated implications. This means that Theorems 1 and 2, as well as the analogous theorems, do not depend on the selection of the fuzzy implication operator. Thus, the choice of the fuzzy implication operator is auxiliary in its nature in such research. More precisely, the results derived in this paper do not affect the selected fuzzy implication at all (the $h$-generated implication in particular). Quite opposite, the $h$-generated implication is exploited to help us complete the investigation. Regarding the soundness of the inference rules for vague functional and multivalued dependencies, we also refer to [32] and [33].

\section{References:}

[1] R. R. Yager, On some new classes of implication operators and their role in approximate reasoning, Inform. Sci. 167, 2004, pp. 193-216.

[2] J. Vilar and M. A. Sanz-Bobi, Semantic analysis of fuzzy models, application to Yager models, in: Mastorakis N. (ed.) Advances in Fuzzy Systems and Evolutionary Computation, Proc. 2nd WSEAS International Conference on Fuzzy Sets and Fuzzy Systems (FSFS 2001), Puerto de la Cruz, Tenerife 2001, pp. 82-87. 
[3] B. Jayaram, Contrapositive symmetrization of fuzzy implications - revisited, Fuzzy Sets and Systems 157, 2006, pp. 2291-2310.

[4] B. Jayaram, Yager's new class of implications $J_{f}$ and some classical tautologies, Inform. Sci. 177, 2007, pp. 930-946.

[5] J. D. Ullman, Principles of Database Systems, Computer Science Press, Rockville, 1982

[6] C. Giardina, I. Sack, and D. Sinha, Fuzzy Field Relational Database Tech. Report 8332, Elect Engng. and Computer Science Dept., Stevens Institute of Technology, Hoboken, 1983

[7] J. F. Baldwin, Knowledge engineering using a fuzzy relational inference language, in: Proc. IFAC Conf. on Fuzzy Information, Knowledge Representation, and Decision Processes, Marseille, France, 1983, pp. 15-23.

[8] H. Prade, The connection between Lipski's approach to incomplete information data bases and Zadeh's Possibility Theory, in: Proc. Int. Conf. System Meth., 1982, pp. 402-408.

[9] H. Prade, Lipski's approach to incomplete information databases restated and generalized in the setting of Zadeh's Possibility Theory, Inform. Systems 9, 1984, pp. 27-42.

[10] H. Prade and C. Testemale, Generalizing database relational algebra for the treatment of incomplete/uncertain informations and vague queries, in: 2nd NAFIP Workshop, 1983.

[11] B. P. Buckles and F. E. Petry, A fuzzy representation of data for relational databases, Fuzzy Sets and Systems 7, 1982, pp. 213-216.

[12] B. P. Buckles and F. E. Petry, Fuzzy databases and their applications, Fuzzy Inform. Decision Process 2, 1982, pp. 361-371.

[13] B. P. Buckles and F. E. Petry, Uncertainty models in information and database systems, J. Inform. Sci. 11, 1985, pp. 77-87.

[14] L. A. Zadeh, Similarity relations and fuzzy orderings, Inform. Sci. 3, 1970, pp. 177-200.

[15] M. Sozat and A. Yazici, A complete axiomatization for fuzzy functional and multivalued dependencies in fuzzy database relations, Fuzzy Sets and Systems 117, 2001, pp. 161-181.

[16] Dž. Gušić, Soundness and Completeness of Inference Rules for New Vague Functional Dependencies, in: N. Mastorakis, V. Mladenov and A. Bulucea (eds.) MATEC Web of Conferences, Vol. 292, 23rd International Conference on Circuits, Systems, Communications and Computers (CSCC 2019), Athens 2019, pp. 1-9.
[17] Dž. Gušić, Soundness of Inference Rules for New Vague Multivalued Dependencies, in: N. Mastorakis, V. Mladenov and A. Bulucea (eds.) MATEC Web of Conferences, Vol. 292, 23rd International Conference on Circuits, Systems, Communications and Computers (CSCC 2019), Athens 2019, pp. 1-7.

[18] Dž. Gušić, Completeness of Inference Rules for New Vague Multivalued Dependencies, WSEAS Trans. on Mathematics 18, 2019, pp. 295-306.

[19] Dž. Gušić, On Completeness of Inference Rules for Vague Functional and Vague Multivalued Dependencies in two-element Vague Relation Instances, WSEAS Trans. on Systems and Control 14, 2019, pp. 232-238.

[20] Dž. Gušić, Vague Functional Dependencies and Resolution Principle, WSEAS Trans. on Mathematics 18, 2019, pp. 288-294.

[21] Dž. Gušić, Vague Multivalued Dependencies and Resolution Principle, WSEAS Trans. on Mathematics 18, 2019, pp. 257-263.

[22] Dž. Gušić and S. Nesimović, New Vague Dependencies as a Result of Automatization, WSEAS Trans. on Systems and Control 14, 2019, pp. 419-436.

[23] N. Dukić, Dž. Gušić, A. Muratović-Ribić, A. Alihodžić, E. Tabak, and H. Dukić, From fuzzy dependences to fuzzy formulas and vice versa, for Kleene-Dienes fuzzy implication operator, WSEAS Trans. on Systems and Control 13, 2018, pp. 285-297.

[24] A. Lu and W. Ng, Managing Merged Data by Vague Functional Dependencies, in: P. Atzeni, W. Chu, H. Lu, S. Zhou, T.-W. Ling (eds.) ER 2004 LNCS, vol. 3288, Springer-Verlag, Berlin Heidelberg 2004, pp. 259-272.

[25] D. H. Hong and C. Kim, A note on Similarity Measures Between Vague Sets and Between Elements, Information Sciences 115, 1999, pp. 8396.

[26] F. Li and Z. Xu, Measures of Similarity Between Vague Sets, Journal of Software 12, 2001, pp. 922-927.

[27] R. C. T. Lee, Fuzzy Logic and the Resolution Principle, J. Assoc. Comput. Mach. 19, 1972, pp. 109-119.

[28] Y. Shi, A Deep Study of Fuzzy Implications, Ph.D. dissertation, Faculty of Science, Ghent University, Ghent, 2009.

[29] M. Baczyński and B. Jayaram, Fuzzy Implications, Berlin-Heidelberg, Springer-Verlag, 2008

[30] M. Baczyński and B. Jayaram, Yager's classes of fuzzy implications: some properties and intersections, Kybernetika 43, 2007, pp. 157-182. 
[31] S. Nesimović and Dž. Gušić, Klir-Yuan Fuzzy Implication in Fuzzy Relations, in: 3rd International Conference on Control, Artificial Intelligence, Robotics and Optimization (ICCAIRO), Athens, Greece, 2019, pp. 163-169.

[32] Dž. Gušić, Z. Šabanac, and S. Nesimović, On Soundness of Various Inference Rules for Vague Functional Dependencies, in: 3rd International Conference on Control, Artificial Intelligence, Robotics and Optimization (ICCAIRO), Athens, Greece, 2019, pp. 182-188.

[33] Dž. Gušić, Z. Šabanac, and S. Nesimović, On Certain Properties of Vague Relation Databases, in: 3rd International Conference on Control, Artificial Intelligence, Robotics and Optimization (ICCAIRO), Athens, Greece, 2019, pp. 195201. 